\title{
Irradiation effects in Generation IV nuclear reactor materials
}

Assel Aitkaliyeva, Lingfeng He, Haiming Wen, Brandon Miller, Xian-Ming Bai, Todd Allen

January 2017

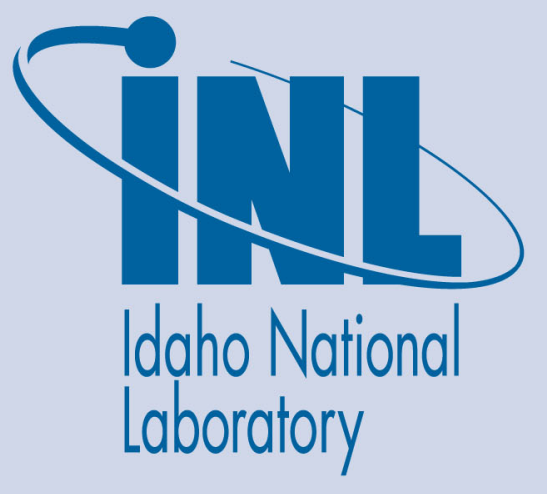

The INL is a U.S. Department of Energy National Laboratory operated by Battelle Energy Alliance 


\section{Irradiation effects in Generation IV nuclear reactor materials}

Assel Aitkaliyeva, Lingfeng He, Haiming Wen, Brandon Miller, Xian-Ming Bai, Todd Allen

January 2017

Idaho National Laboratory Idaho Falls, Idaho 83415

http://www.inl.gov

Prepared for the

U.S. Department of Energy

Under DOE Idaho Operations Office

Contract DE-AC07-05ID14517 


\title{
Irradiation effects in Generation IV nuclear reactor materials
}

Assel Aitkaliyeva, ${ }^{\S}$ Lingfeng He, ${ }^{\S}$ Haiming Wen, ${ }^{\S}$ Brandon Miller, ${ }^{\S}$ Xian-Ming Bai, ${ }^{\S}$ Todd

\author{
Allen $^{\S} *$ \\ Idaho National Laboratory, Idaho Falls, ID, 83415, USA \\ ${ }^{\S}$ Authors contributed equally. \\ *Idaho National Laboratory, P.O. Box 1625, M.S. 3634, Idaho Falls, ID 83415-3634, \\ Todd.Allen@inl.gov, T: +1-208-526-8096, F: +1-208-526-4563.
}

\section{Keywords}

Irradiation induced defects; solute segregation; phase transformations; characterization techniques; mesoscale modeling

\begin{abstract}
Generation IV reactor structural materials will be exposed to high doses and temperatures during reactor operation that may lead to irradiation-induced degradation. This degradation will differ from that seen in light water reactors and therefore understanding mechanisms controlling material performance during irradiation is critical for evaluating viability of Generation IV nuclear reactor concepts. This chapter discusses irradiation effects and microstructural changes that affect mechanical properties and dimensional stability of Generation IV reactor materials.
\end{abstract}

\section{Introduction}

Structural materials in nuclear reactors are subjected to irradiation-induced degradation as irradiation creates a supersaturation of point defects leading to defect clusters unique to irradiation [1]. The aggregation of the defects and clusters produced during irradiation induces 
complex microstructural features such as voids and dislocation loops, imbalanced segregation of alloy elements to sinks, radiation enhanced or induced precipitation of second phases, and formation of patterned structures. These radiation-induced microstructures affect the physical properties of materials. Commonly observed macroscopic consequences of irradiation are hardening, embrittlement, and dimensional changes (creep, swelling, and growth). Complexity of the microstructure and the challenges involved with characterization of these microstructures at the relevant micro- and nano-scales complicate establishing the relationship between microstructure and physical properties of the material. This chapter will concentrate on the microstructural changes that are responsible for mechanical property and dimensional degradation.

In Generation IV reactors, the structural materials will be exposed to much higher irradiation dose and operated at much higher temperatures than in current light water reactors [2]. Figure 1 shows the operation temperature window and irradiation dose in displacement per atom (dpa) for different Generation IV nuclear reactor systems [1]. As a result, the radiation effects will be more pronounced in Generation IV reactor materials as compared to those in light water reactor materials. The main requirements for the materials to be used in Gen IV reactors include good dimensional stability under irradiation with stress (e.g., irradiation creep) or without stress (e.g., void swelling and irradiation growth), resilient mechanical properties (such as tensile strength, ductility, creep resistance, and fracture toughness) after ageing, and high degree of chemical compatibility with the coolant and the fuel. In regard to the chemical compatibility, the resistance to stress corrosion cracking and irradiation-assisted stress corrosion cracking (IASCC) is very important. These requirements have to be met not only under normal operation conditions but also under accident conditions. The combination of high temperature, 
high irradiation doses, and chemically harsh environment poses a unique challenge to the performance of structural materials. Thus, understanding the microstructural evolution and the associated physical property changes is the key to designing radiation-tolerant materials in Generation IV reactors.

This chapter will discuss the macroscopic and microscopic properties in Generation IV reactor materials, and the advances in characterization of irradiation-induced defects and in mesoscale modeling of irradiation damage. The majority of the examples provided are based on ferritic-martensitic (F-M) steels, even though they might not always be primary candidates for GEN IV reactors, but the reported defects and microstructural features are typical to other irradiated alloys, and F-M steels are used as an illustrative example. In some cases, comparisons will be made to austenitic steels to illustrate how differences in structure and alloy composition can cause large differences in radiation response.

The rest of the chapter is divided into three sections. A brief description of the radiation effects in materials is provided in Section 2. For a detailed description of the various radiation effects in structural and functional materials, readers can consult reference [3], in which a much great level of details are provided in 5 volumes. In addition, Section 2 discusses radiation induced defects, solute segregation, and phase transformations in Generation IV reactor materials. Section 3 focuses on the techniques used for characterization of defects in irradiated materials and the advances made in the past 10 years. The discussion on mesoscale modeling of radiation damage is provided in Section 4 . 


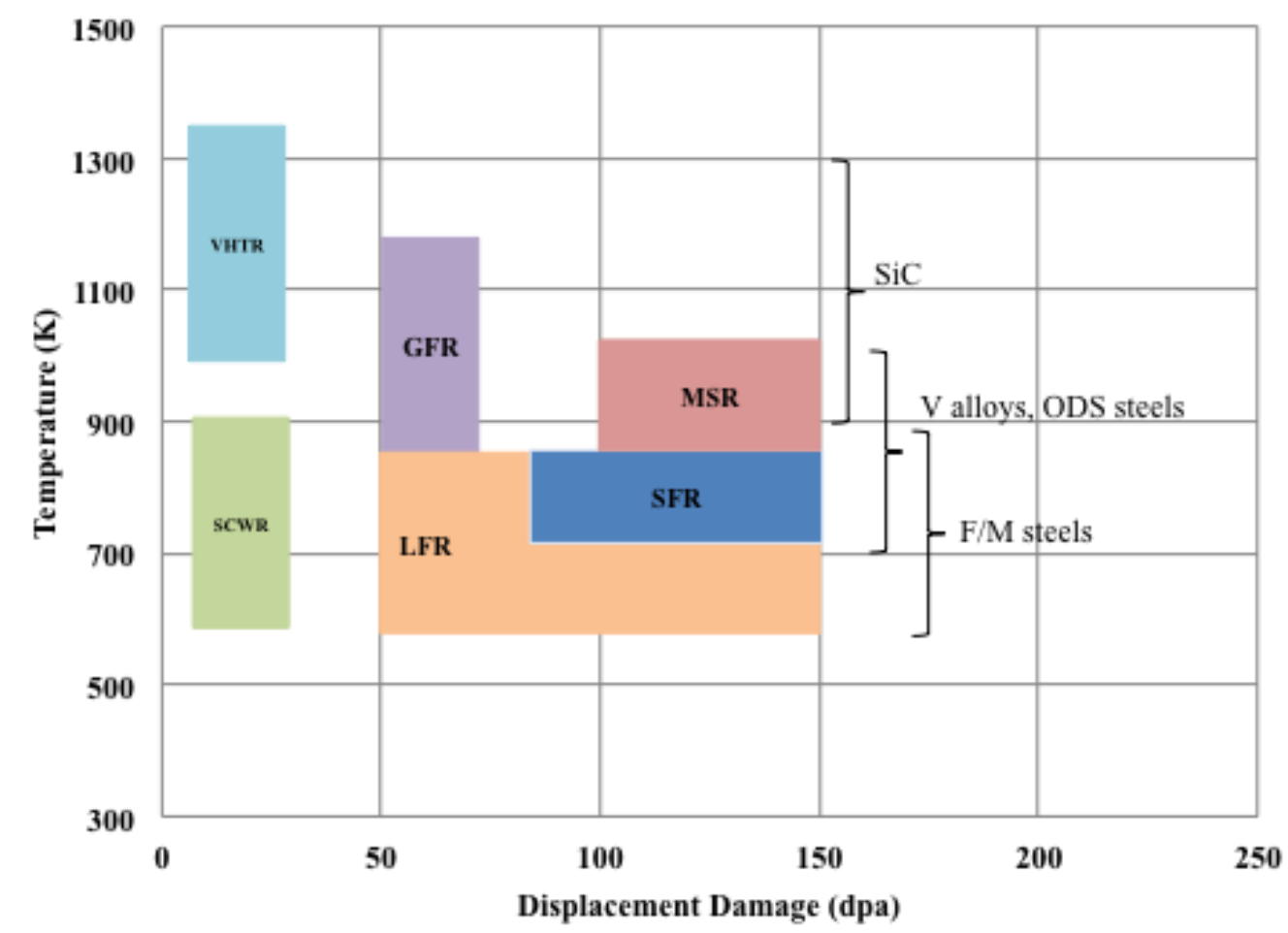

Fig. 1. Operation temperature window and irradiation dose range for Gen IV reactors [1]. VTHR stands for Very High Temperature Reactor; SCWR for Super Critical Water Reactor; GFR for Gas-cooled Fast Reactor; LFR for Lead-alloy cooled Fast Reactor; SFR for Sodium-cooled Fast Reactor; MSR for Molten Salt Reactor.

\section{Radiation damage process}

A thorough understanding of the mechanisms controlling material degradation upon irradiation is required to evaluate the viability of Generation IV reactor systems. A number of processes occur during irradiation and Fig. 2 provides a unified picture of how irradiation interacts with and alters the structure and properties of the materials, and how different processes are interconnected. The detailed description of these processes is provided below. 


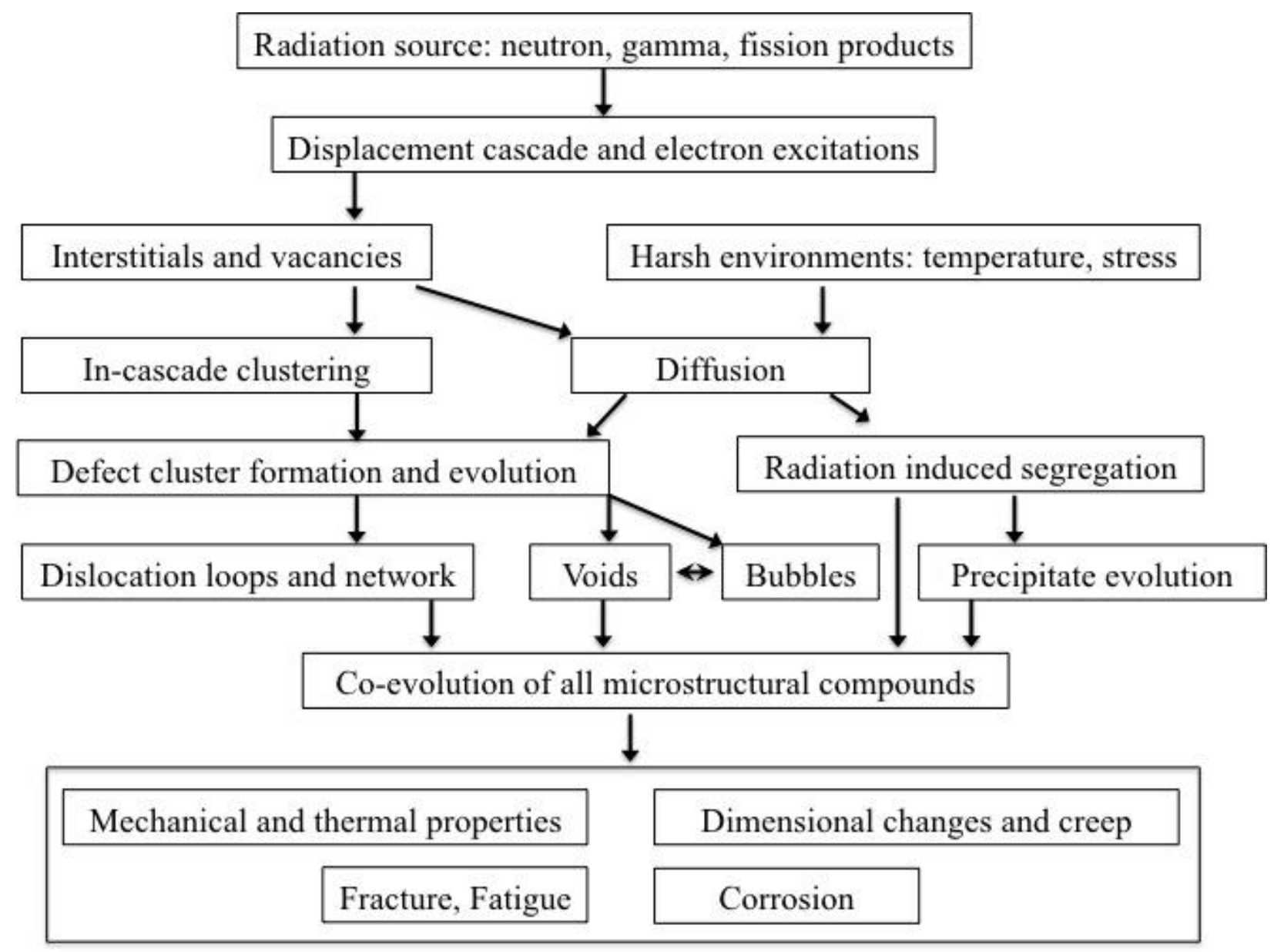

Fig. 2. Schematic representation of the connection between different processes occurring during irradiation of materials.

High-energy particles, such as electrons, ions, or neutrons with energies larger than several tens of $\mathrm{eV}$, can induce displacement of atoms from their normal lattice positions. The first atom displaced by a high-energy particle (the so-called primary knock-on atoms, PKA) transfers energy to its surrounding atoms, and often displaces some of them, which, in turn, may result in a "displacement cascade." The extent of the displacement damage is conventionally expressed in terms of the displacements per atom (dpa), which is the calculated average number of times that each atom has been displaced from the lattice position during the irradiation. Doses 
in the order of 100-200 dpa can be accumulated over the lifetimes of some structural components in various high-flux reactors $[1,3]$.

The displacement process produces two types of crystalline point defects, vacant crystalline positions (vacancies) and displaced atoms in interstitial crystalline positions (interstitials). Vacancy and interstitial clusters are also created directly from displacement cascades. Molecular Dynamics (MD) simulations show that the fraction of point defects surviving after the displacement cascade completely cools down is eventually only $20 \%-40 \%$ of that predicted by the Norgett Robinson and Torrens (NRT) model [4] that predicts displacements solely on distributing energy to knock-ons without considering recombination during the cascade process [5]. The presence of excess vacancies and interstitials is the origin of the irradiation effects on materials properties [6]. At reactor operating temperatures, both defect types in metals are mobile and most are eliminated by a one-to-one recombination (annihilation) and have no or little effect on materials properties. Those that do not recombine can form agglomerations of various types and geometries (e.g. dislocation loops and voids), affecting materials properties. Interstitials and vacancies also likely migrate to sinks, including surfaces, grain boundaries, precipitate/matrix interfaces, dislocations and cavities, where they are absorbed. If vacancies and interstitials are accepted equally at the sinks, they also annihilate. If either the vacancies or interstitials are accepted preferentially at sinks, the damage accumulates and materials properties are affected from the resulting microstructural features.

\subsection{Irradiation induced point and line defects in steels}

Interstitial clusters can evolve into dislocation loops and vacancy clusters can develop into vacancy loops or cavities. These clusters can contribute to changes in both mechanical 
properties and dimension. The types of defect clusters formed under radiation depend on the alloy crystal structure (e.g., bcc vs. fcc), alloy composition, and temperature, as discussed below.

Below $0.3 \mathrm{~T}_{\mathrm{m}}$, where $\mathrm{T}_{\mathrm{m}}$ is the absolute melting point of the irradiated material, interstitials have higher mobility than vacancies so that interstitials aggregate to form prismatic dislocation loops before vacancies form voids. Dislocation loops with two Burgers vector orientations have been observed in pure iron and F-M steels: edge loops with <100> Burgers vectors on $\{200\}$ planes and edge loops with $1 / 2<111>$ Burgers vectors on $\{111\}$ planes $[6,7]$. Other habit plane for $1 / 2<111>$ loops, $\{110\}$ has also been predicted by simulation but not yet verified by experiments [7]. Fig. 3 shows the coexistence of these two types of loops in F-M steels. Most loops, if not all, are interstitial loops in F-M steels [7]. $1 / 2<111>$ loops are glissile and $\langle 100\rangle$ loops can be considered sessile in ferritics based on the planar geometries of large loops following irradiation.

The relative stability of $1 / 2<111>$ and $<100>$ dislocation loops in pure $\mathrm{Fe}$ and bcc $\mathrm{Fe}-\mathrm{Cr}$ alloys was determined as a function of temperature under $\mathrm{Fe}^{+}$self ion irradiation [8]. Figure 4 shows the fraction of two types of dislocation loops as a function of irradiation temperature. For pure iron, the microstructure was dominated by $1 / 2<111>$ interstitial loops at temperatures $T_{\text {irr }} \leq$ $300^{\circ} \mathrm{C}$, although small $<100>$ loops were still present even at room temperature. At temperatures $\mathrm{T}_{\text {irr }} \geq 400^{\circ} \mathrm{C},<100>$ loops became more dominant than $1 / 2<111>$ loops. At temperatures $\mathrm{T}_{\text {irr }} \geq$ $450^{\circ} \mathrm{C}$, small, mobile $1 / 2<111>$ loops were subsumed by sessile $<100>$ loops and large $1 / 2<111>$ loops were not observed. At $500^{\circ} \mathrm{C},<100>$ loops developed into large networks, and no visible $1 / 2<111>$ loop formed [8]. 

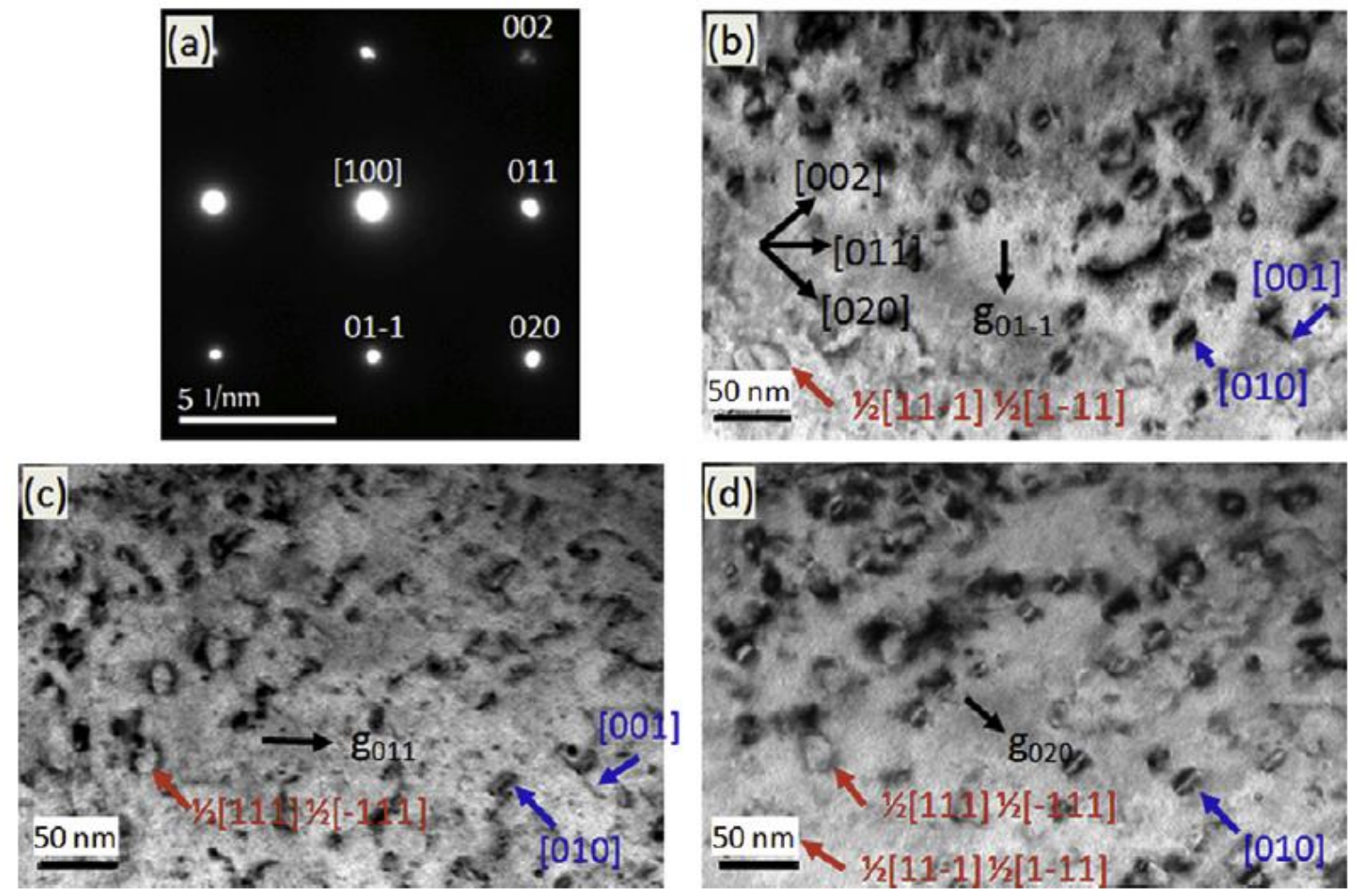

Fig. 3. Transmission electron microscopy (TEM) acquired diffraction pattern (a) under [100] axis, and corresponding bright-field images using (b) $g_{01 \overline{1}}$, (c) $g_{011}$, and (d) $g_{020}$ diffraction vectors near the zone axis of reduced activation ferritic/martensitic (RAFM) steels irradiated with neutrons up to $3.9 \mathrm{dpa}$ at $400^{\circ} \mathrm{C}$ [7]. 


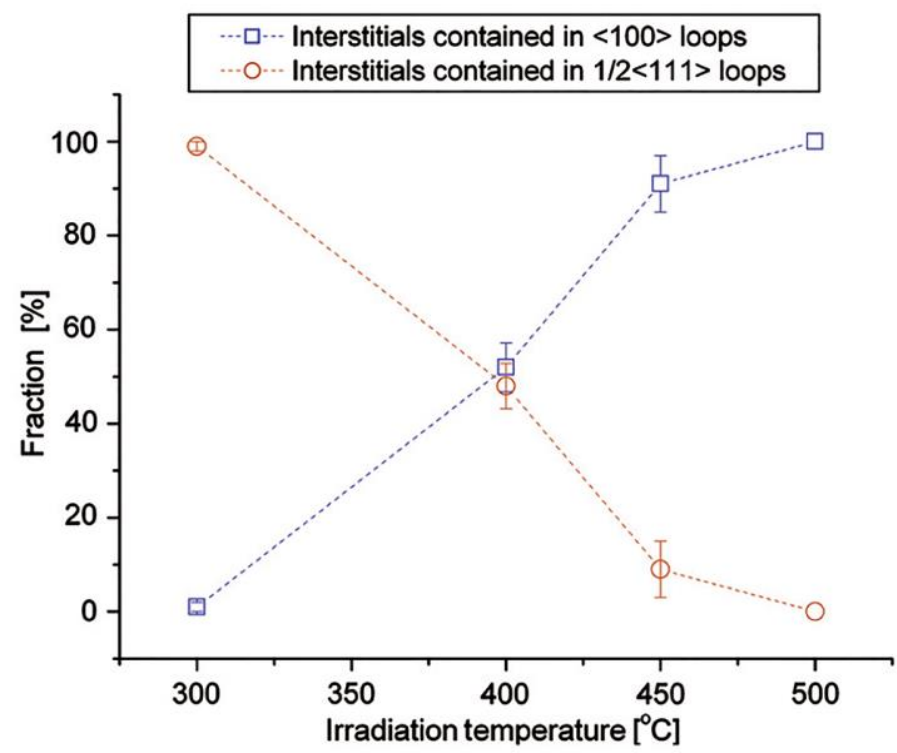

Fig. 4. Fraction of interstitials contained in loops of the two types as a function of temperature in pure Fe [8].

The fractions of the two loop types are probably determined by their temperaturedependent relative stabilities [9] and increased mobility of $1 / 2<111>$ loops at higher temperatures. For example, the theoretical calculations by Dudarev et al. [9] showed that the reduction of shear stiffness constant $c^{\prime}=\left(c_{11}-c_{12}\right) / 2$ with increasing temperature has a profound effect on the relative stability of $1 / 2<111>$ and $<100>$ loops. In agreement with experimental observation (Fig. 4), their calculations showed that the hexagonal $1 / 2<111>$ prismatic pure-edge loops are most stable at low temperature $<350^{\circ} \mathrm{C}$ while $<100>$ pure-edge loops are more stable at higher temperatures. The irradiation in reactors is more complicated than ion irradiation and the proportion of two loop types in Fe in neutron irradiation is not always in agreement with that observed in ion irradiation. Predominant $<100>$ loops in the microstructure of Fe under neutron irradiation around $300^{\circ} \mathrm{C}$ have been reported by different researchers [10-13].

Composition can affect the types of loops formed under radiation. In Fe-Cr alloys, the 
damage structures as a function of temperature are basically similar to those in pure $\mathrm{Fe}$ under $\mathrm{Fe}^{+}$ self-ion irradiation, but the loop size in Fe-Cr alloys is much smaller than that in pure Fe [14]. Moreover, the proportions of two loop types in $\mathrm{Fe}-\mathrm{Cr}$ alloys are also affected by the alloy composition [15]. The fraction of $1 / 2<111>$ loops increases with $\mathrm{Cr}$ content after neutron irradiation at $400-450^{\circ} \mathrm{C}$ to $15 \mathrm{dpa}$ [16-17]. <100> dislocation loops were predominant in the microstructure in $\mathrm{Fe}-\mathrm{Cr}$ alloys with $\mathrm{Cr}$ content less than $6 \%$ and a mixed $\langle 100\rangle$ and $1 / 2<111>$ loops formed in $\mathrm{Fe}-\mathrm{Cr}$ alloys with higher $\mathrm{Cr}$ content under neutron irradiation at $400^{\circ} \mathrm{C}$ [15]. In addition, the presence of $\mathrm{Cr}$ in a $\mathrm{Fe}-\mathrm{Cr}$ binary alloy can remarkably decrease the size of the interstitial loops after neutron irradiation $[11,18]$. The ratio and size of $1 / 2<111\rangle$ and $\langle 100\rangle$ dislocations and/or dislocation loops have some effects (although moderate) on radiation hardening because higher mobility of $1 / 2<111>$ dislocation loops could result in their almost complete disappearance via annihilation at the surface. In Fe-Cr alloys, the suppression of mobility of interstitial defects by $\mathrm{Cr}$ atoms results in a higher recombination rate and leads to delays in the formation of visible defects [10-11]. Similar effects on loop size and type may also come from other constituent elements, such as $\mathrm{Ni}$ as well as interstitial atoms such as $\mathrm{C}$ and $\mathrm{N}$ [19].

In austenitic steels (fcc structure), the primary type of irradiation induced dislocation loops are faulted interstitial Frank loops, lying on the $\{111\}$ planes with a Burgers vector of $1 / 3<111>$. Frank loops result from the clustering of self-interstitial atoms (SIAs) and they are sessile. Figure 5 shows an example of Frank loops in neutron irradiated 316SS [20]. Frank loops grow with dose and temperature during irradiation, and may unfault and form a dislocation network at high temperatures. Detailed dislocation evolution information such as size and density as a function of dose and temperature in austenitic steels can be found in review papers 
[21-22].
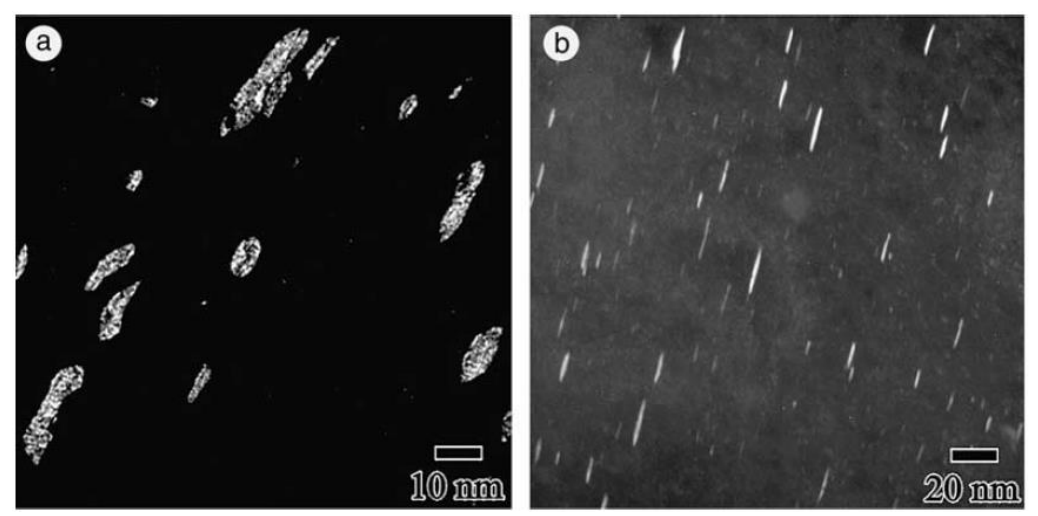

Fig. 5. Dark field micrographs of the Frank loops using their rel-rod near a $g=113$ two beam condition in neutron-irradiated 316SS are shown inclined in (a) and on edge in (b). [20].

\subsection{Volume defects in steels}

Another defect configuration that can form in irradiated fcc metals or alloys (e.g. austenitic steels) is the stacking fault tetrahedron (SFT). A SFT is a three-dimensional stacking fault configuration in the shape of a tetrahedron. SFTs are identified by their triangular images in weak-beam or two-beam conditions when observed from $\langle 110\rangle$ direction. An example is shown in Fig. 6. SFTs can form in austenitic steels irradiated under a cascade regime (ion and neutron irradiation) as well as under Frenkel pair regime (electron irradiation). Two formation mechanisms have been proposed based on experimental observation and MD simulations: i) SFTs form directly in the displacement cascade; ii) SFTs stem from the condensation of vacancies in the supersaturated lattice [23]. The interactions between mobile dislocations and SFTs cause changes in the mechanical properties, such as strengthening, hardening and plastic instability during deformation. 


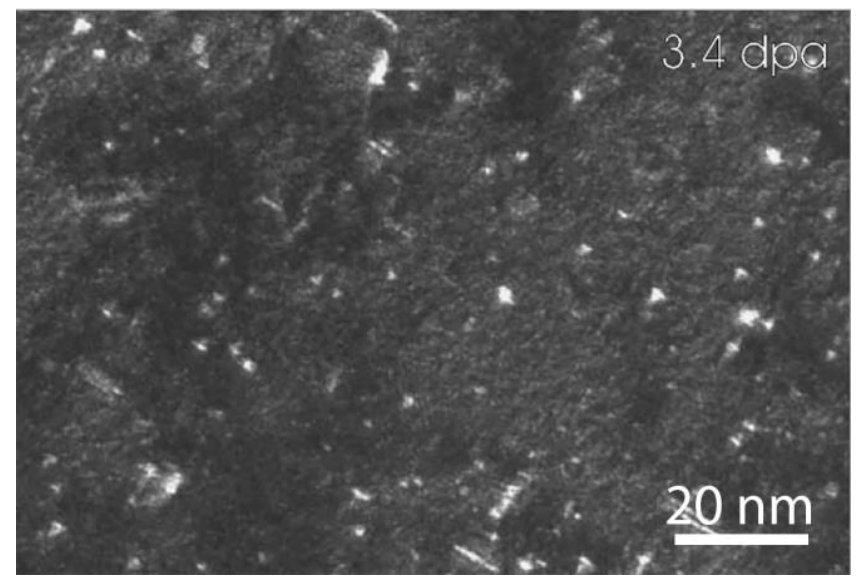

Fig. 6. Weak beam dark-field graph showing the microstructure in 304 stainless steels irradiated at 3.4 dpa. The triangle-shape clusters are stacking fault tetrahedra [24].

The elastic interactions between interstitials and dislocations are stronger than those between vacancies and dislocations - the so-called "dislocation bias". A biased attraction between interstitials and dislocations or dislocation loops leads to a preferential flux of interstitials toward dislocations [25]. As a result, excess vacancies become supersaturated, and cavity nucleation and growth takes place when the irradiation temperature is above $0.3 \mathrm{~T}_{\mathrm{m}}$. This agglomeration of vacancies into voids or bubbles is associated with a net volume increase known as void swelling. Figure 7 shows the cavities in neutron-irradiated $\mathrm{Fe}$ and $\mathrm{Fe}-12 \mathrm{Cr}$ alloy. Clearly, the density of the cavities in the Fe-12Cr alloy is lower and the sizes are also much smaller than those in the pure iron, suggesting that Fe-Cr alloys have a better swelling resistance than pure iron. Two types of cavities can form: bubbles and voids. Bubbles contain gas atoms while voids do not contain gas atoms. For most engineering applications in nuclear systems, void swelling is the most important contributor to dimensional instability [5]. 

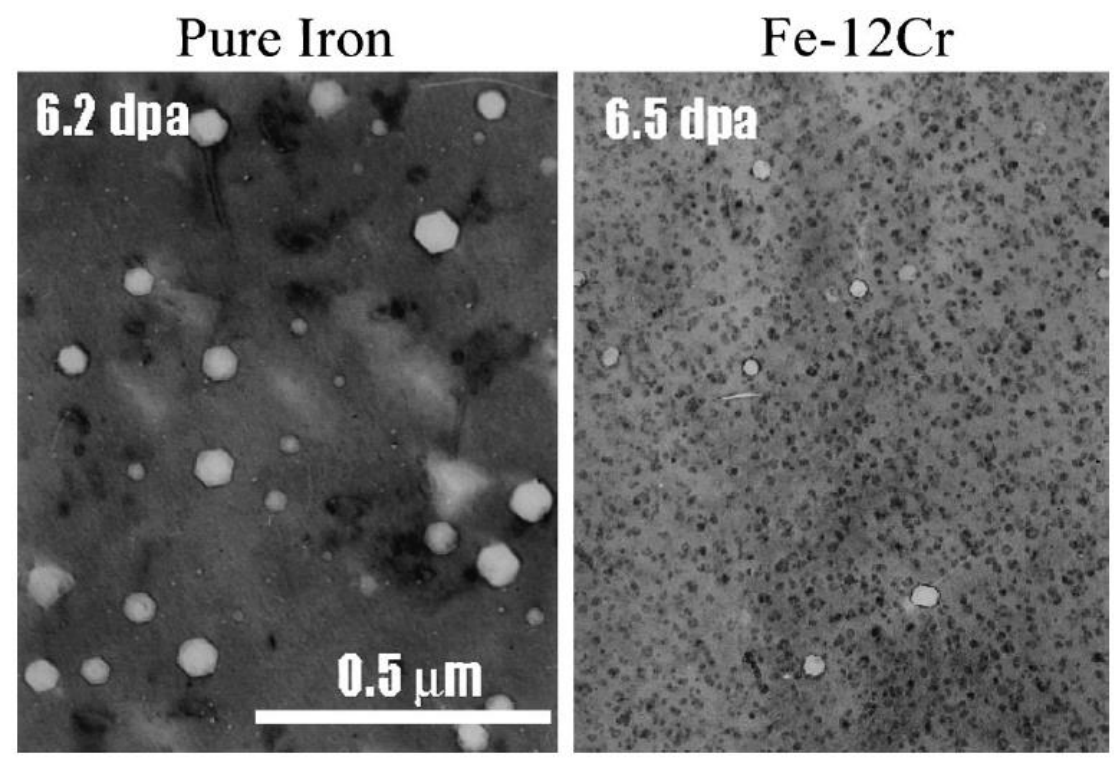

Fig. 7. Microstructures of pure iron and Fe-12Cr alloy after neutron irradiation at $400^{\circ} \mathrm{C}$ to $\sim 6$ dpa [26].

It is well known that bcc steels (ferritic and F-M steels) develop much less swelling than fcc steels (austenitic steels) during irradiation. The typical dose dependence of swelling for F-M steels and austenitic steels is shown in Fig. 8. The lower swelling of bcc steels is primarily due to much longer transient regimes (incubation period) prior to the onset of steady-state swelling. The steady-state swelling rate in F-M steels and austenitic steels are roughly $0.2 \% / \mathrm{dpa}$ and 1\%/dpa, respectively [26]. The swelling in F-M alloys depends on the $\mathrm{Cr}$ concentration and in general it peaks at intermediate $\mathrm{Cr}$ level $(6-9 \%)[17,27]$, although some work showed that a 5\% Cr level gave the lowest swelling [28]. The carbon addition also showed a significant effect on the swelling behavior in Fe-12Cr at high temperatures [27]. 


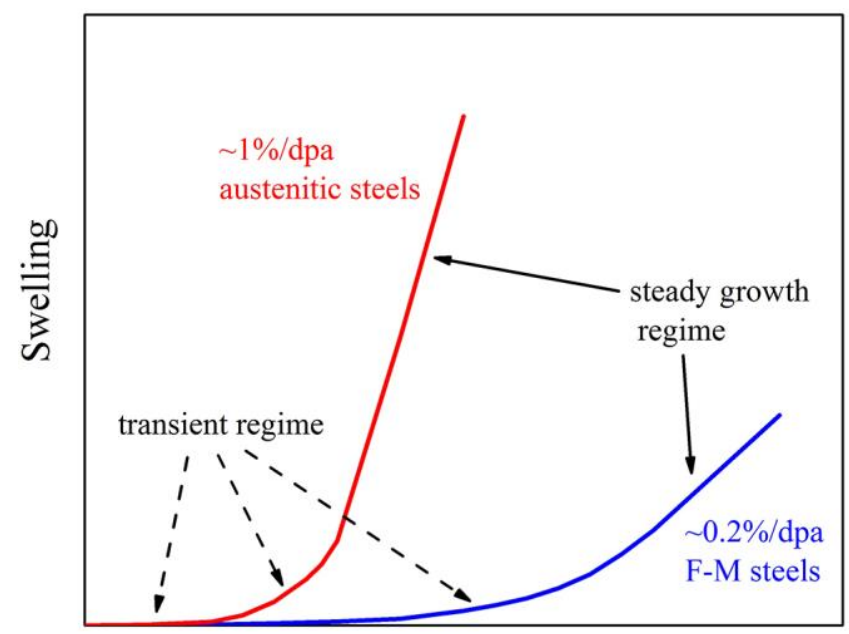

Dose (dpa)

Fig. 8. Dose dependence of swelling for F-M steels and austenitic steels.

The nucleation of cavities dictates the transient regimes for radiation swelling and the growth of cavities leads to the steady-state swelling (terminal swelling). The duration of the transient regimes depends on temperature, dose rate, and initial characteristics like dislocation density and solute concentrations. The subsequent steady state swelling is largely independent of temperature and dose rate, instead being determined by the intrinsic material properties [29].

The swelling response can be altered by varying the structure of the steel or by adding a number of defect sinks that compete with voids for available point defects. The excellent swelling resistance of F-M steels with respect to austenitic steels can be ascribed to their bcc crystal structure and complicated defect-sink interactions. Several explanations summarized by Klueh and Harries [6] are: (i) solute trapping caused by weak interactions between $\mathrm{Cr}$ and vacancies, (ii) the character of dislocation loop structure, (iii) a lower dislocation bias for interstitials in bcc alloys than in fcc alloys, and (iv) the extensive subgrain and lath boundaries in tempered martensite microstructure. However, none of the proposed mechanisms can completely explain the low-swelling observations. In addition, a high density of second phase precipitates, 
e.g. Y-Ti-O nano-precipitates in oxide dispersion strengthened (ODS) steels produces numerous precipitate/matrix interfaces, which act as sinks, have very high point defect capture efficiency and can absorb a number of point defects of either kind. Thus, these precipitates containing materials show good resistance to swelling [30]. Like precipitate/matrix interfaces, grain boundaries are also important sinks that inhibit void nucleation and swelling in steels. The average void swelling rate of coarse-grained 304SS is $\sim 0.18 \% / \mathrm{dpa}$, while that for ultrafine grained counterpart (grain size of $\sim 100 \mathrm{~nm}$ ) is only $\sim 0.03 \% / \mathrm{dpa}[31]$.

\subsection{Radiation-induced segregation in steels}

During irradiation in alloys, radiation-produced point defects diffuse in coupling with the solute diffusion. When a given alloying component has a preferential association with the defect flux that flows towards sinks such as grain boundaries, segregation of the alloy element at the sinks occurs [32]. Based on the relative interaction of each element with the defect flux, enrichment or depletion of each element occurs [32]. This segregation is termed radiationinduced segregation (RIS). RIS typically occurs at intermediate temperatures $(30 \%-50 \%$ of melting temperature) for alloys. At low temperatures, diffusion is not significant for segregation to occur. At high temperatures, the large concentration of thermal defects leads to rapid backdiffusion and elimination of radiation-produced segregation [33].

Radiation-induced depletion of $\mathrm{Cr}$ at grain boundaries in austenitic steels is a potential contributor to intergranular irradiation-assisted stress corrosion cracking (IASCC) of stainless steel reactor vessel internal components, which poses a serious threat to the integrity of core components [32, 34]. A damage of 1-10 dpa is the dose range over which IASCC is first evident, although studies have not provided a definitive connection between grain boundary composition 
and IASCC susceptibility $[32,35]$. In F-M alloys, enrichment of Cr by RIS and the subsequent formation of $\alpha^{\prime}$ or a variety of intermetallic phases may embrittle the alloy, and significant depletion of $\mathrm{Cr}$ may dramatically alter the corrosion resistance of grain boundaries [33]. Irradiation-induced intergranular segregation of impurity atoms, like $\mathrm{P}$ and $\mathrm{Si}$, occurs in several high Cr ferritic steels (9-12 wt\%) [36]. Such impurity segregation plays an important role in irradiation-induced embrittlement; the Charpy impact test ductile-to-brittle transition temperature (DBTT) will increase due to the embrittlement [37, 38].

RIS in austenitic steels has been well studied. For example, in irradiated 304 stainless steel, the $\mathrm{Cr}$ that is added for corrosion resistance can be depleted at grain boundaries, while elements such as $\mathrm{Ni}$ and $\mathrm{Si}$ are enriched [32]. This can change the composition of grain boundaries and change their corrosion response. Figure 9 shows a typical RIS profile for $\mathrm{Cr}, \mathrm{Ni}$ and minor elements at the grain boundary of a neutron irradiated stainless steel [33, 22]. At 290$310^{\circ} \mathrm{C}$, the depletion of $\mathrm{Cr}$ and enrichment of $\mathrm{Ni}$ and $\mathrm{Si}$ get larger as a function of irradiation dose; Cr decreases from bulk levels (20-24 wt.\%) to 12-16 wt.\% after 5-10 dpa, and Si enriches to as high as $10 \%$ by 10 dpa $[32,22,39]$. 


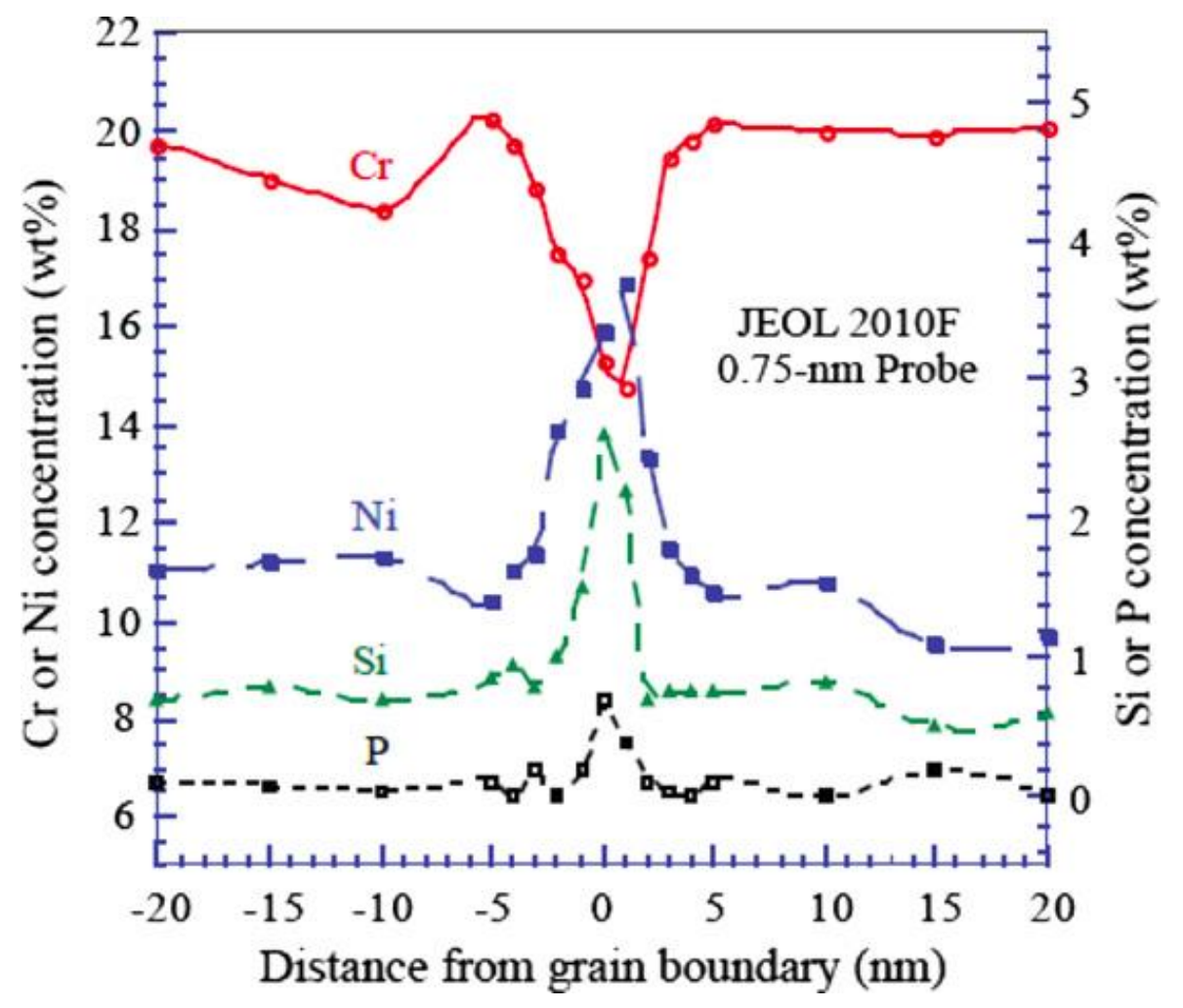

Fig. 9. Radiation-induced segregation of $\mathrm{Cr}, \mathrm{Ni}, \mathrm{Si}$ and $\mathrm{P}$ at a grain boundary in a 300 series stainless steel irradiated to several dpa at $300{ }^{\circ} \mathrm{C}[33,22]$. 


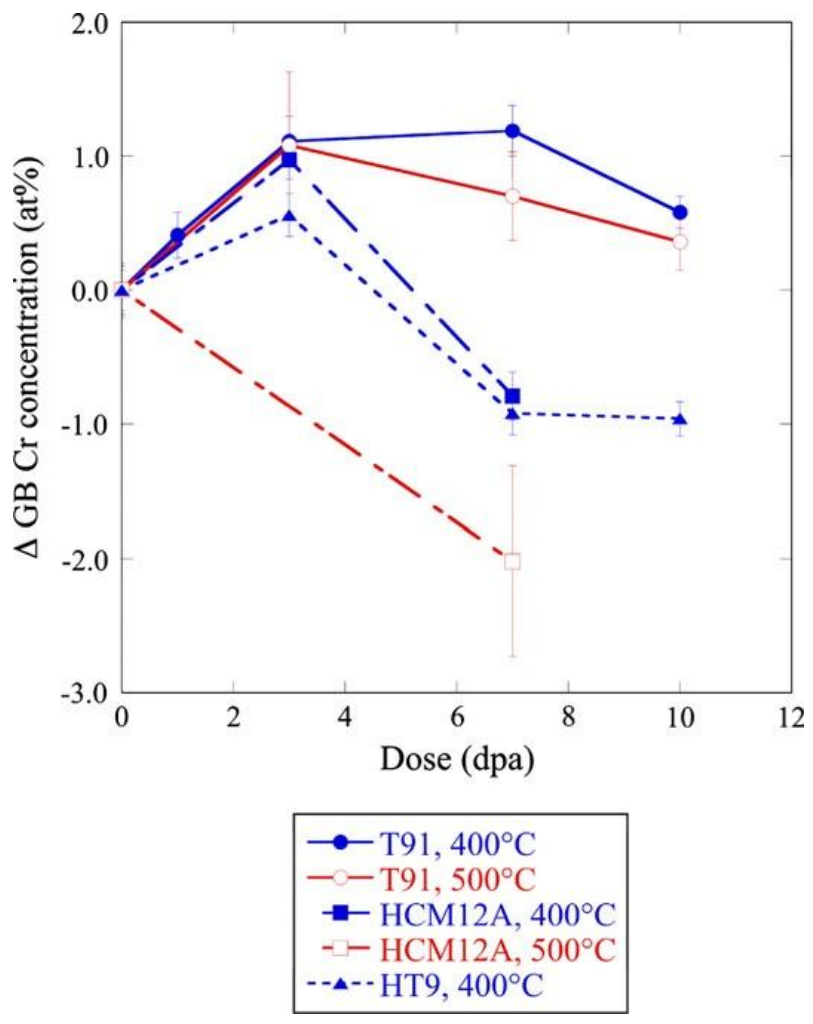

Fig. 10. Amount of Cr RIS from proton irradiation experiments as a function of dose for a range of F-M alloys and temperatures [40].

Two mechanisms have been proposed for RIS in $\mathrm{Fe}-\mathrm{Cr}-\mathrm{Ni}$ austenitic alloys [33, 41, 42]. One is the preferential exchange of an alloying element with the vacancy flux resulting in a net solute flux toward or away from the boundary (the vacancy mechanism portion of the inverse Kirkendall effect) [42]. The second mechanism is the preferential association of undersized atoms (such as $\mathrm{Ni}$ ) with the interstitial flux (interstitial binding). In the interstitial binding model, both interstitial binding and preferential association of solutes with the vacancy flux contribute to the segregation [33].

In a comprehensive study of RIS mechanisms, seven $\mathrm{Fe}-\mathrm{Cr}-\mathrm{Ni}$ alloys were irradiated with 3.2 $\mathrm{MeV}$ protons at temperatures from $200{ }^{\circ} \mathrm{C}$ to $600{ }^{\circ} \mathrm{C}$ and to doses from 0.1 to $3 \mathrm{dpa}$ [43]. 
Grain boundary compositions were measured and compared to model predictions. Predictions that assumed segregation was driven by preferential interaction of solute atoms with the vacancy flux alone were generally consistent with the segregation measurements, whereas the inclusion of interstitial binding to the inverse Kirkendall (IK) model caused poor agreement with the experimental results [43]. The primary driving mechanism for segregation in $\mathrm{Fe}-\mathrm{Cr}-\mathrm{Ni}$ alloys was shown to be consistent with the coupling between alloying elements and the vacancy flux. In addition, the IK model was improved by the inclusion of composition dependent migration energies that include the effect of short-range order [44]. The modified IK model produced results in good agreement with measurements for both $\mathrm{Cr}$ and $\mathrm{Ni}$ at the grain boundary, for a range of alloys with different irradiation temperatures and doses.

Although observations of RIS in $\mathrm{Fe}-\mathrm{Cr}-\mathrm{Ni}$ alloys are adequately explained by a vacancy exchange mechanism, it was proposed that RIS during electron irradiation at high dose rates and low temperatures can only be explained by the binding of Ni atoms to interstitials with a binding energy of $0.75 \mathrm{eV}[45,46]$. In addition, ab initio based modeling has demonstrated that the observed Cr RIS in fcc steels may be a balance between two large RIS tendencies, one for depletion (driven by vacancy flux) and the other one for enrichment (driven by interstitial flux) [47].

While the RIS over a wide range of austenitic alloys is consistent, the RIS behavior in F$\mathrm{M}$ alloys is much less consistent. Of the 15 measurements of RIS in irradiated F-M alloys reviewed in [48], eight showed grain boundary $\mathrm{Cr}$ enrichment and seven exhibited depletion; the irradiation conditions varied significantly among the data and there were no data points taken under the same irradiation conditions. Three alloys, T91, HT9 and HCM12A, were irradiated from 3 to $10 \mathrm{dpa}$ at both $400{ }^{\circ} \mathrm{C}$ and $500{ }^{\circ} \mathrm{C}$ with $2.0 \mathrm{MeV}$ protons and a dose rate of 
approximately $1.3 \times 10^{-5} \mathrm{dpa} / \mathrm{s}[33,49]$. The results are summarized in Fig. 10 [40]. Results indicated that irradiation at $400{ }^{\circ} \mathrm{C}$ results in grain boundary enrichment of $\mathrm{Cr}$ in $\mathrm{T} 91$ by $3 \mathrm{dpa}$, after which the $\mathrm{Cr}$ concentration profiles flatten and broaden; for HCM12A, there is no measurable $\mathrm{Cr}$ segregation at $3 \mathrm{dpa}$, but $\mathrm{Cr}$ depletion occurs at $7 \mathrm{dpa}$; for $\mathrm{HT} 9$, there is a small $\mathrm{Cr}$ enrichment at $3 \mathrm{dpa}$, and depletion at 7 and $10 \mathrm{dpa}[33,49]$. At $500{ }^{\circ} \mathrm{C}$, irradiation of T91 results in $\mathrm{Cr}$ enrichment at all doses, and irradiation of HCM12A leads to significant $\mathrm{Cr}$ depletion at 7 dpa [33]. Hence, RIS in F-M alloys depends on the alloy composition and irradiation temperature, with grain boundary $\mathrm{Cr}$ enrichment in the alloy with lower $\mathrm{Cr}$ (T91) and at $400{ }^{\circ} \mathrm{C}$, and depletion in higher Cr alloys (HT9 and HCM12A) and at higher irradiation temperature [33]. The temperature- and composition-dependent RIS behavior in F-M alloys has been modeled with rate theory modeling recently, as discussed in the modeling section of this chapter.

\subsection{Irradiation induced precipitation}

In addition to RIS, radiation can cause precipitation of second phases in alloys. Typically there are two types of precipitation mechanisms: (i) radiation-enhanced mechanism in which the precipitation is thermodynamically favorable and the high concentration of point defects under irradiation allows supersaturated solutes to achieve equilibrium through precipitation at significant faster rates than under thermal conditions; and (ii) radiation-induced mechanism in which the coupling between migrating point defects and solute atoms can induce a nonequilibrium state and modify the composition range of the expected phases [50]. Therefore, in the former precipitation can occur under thermal aging without irradiation while in the latter the precipitation only occurs under irradiation. The precipitates can become obstacles for dislocation motion and result in radiation-induced hardening and embrittlement. The precipitates can also 
initiate radiation-induced strain processes in stainless steels, which, when saturated in magnitude, can be a significant portion of the total net strain at low dpa levels and can complicate the analysis of void swelling and irradiation creep. The new radiation-stabilized precipitates can affect the microstructure at higher doses and cause development of high density of crystallographically faceted voids, and thus result in swelling of the material.

For example, the formation of non-equilibrium gamma, gamma prime, and $\mathrm{G}$ phase have all been observed in 316 stainless steels [32]. Both RIS and RIP are observed in the $250-300{ }^{\circ} \mathrm{C}$ range in 300 series austenitic stainless steels. Due to enrichment of nickel and silicon at defect sinks, the G-phase silicides are present after modest irradiation fluences [48]. In addition, many other types of phases have been observed in irradiated stainless steels, including carbides, Laves and gamma [32]. The extent of precipitation and type of precipitate are extremely sensitive to the exact temperature, dose and dose rate, but are also dependent on the specific damage microstructure.

In F/M steels, irradiation can induce formation of $\mathrm{M}_{6} \mathrm{C}(\eta), \alpha^{\prime}, \chi, \mathrm{G}$ phase, $\mathrm{Cr}_{2} \mathrm{X}, \sigma, \mathrm{Cr}_{3} \mathrm{P}$ or MP phases. $\eta, \alpha^{\prime}, \chi, \mathrm{Cr}_{2} \mathrm{X}, \sigma, \mathrm{Cr}_{3} \mathrm{P}$ and MP are all Cr-rich phases [33, 48]. The formation of precipitates depends on the composition and irradiation temperature. For example, $\eta$ was observed in $9-12 \mathrm{Cr}$ steels that contain $>0.3 \mathrm{wt} . \% \mathrm{Ni}$ irradiated at $380{ }^{\circ} \mathrm{C}$ or above [48].

Bachhav et al. [50] reported studies of solute distributions in a series of model $\mathrm{Fe}-\mathrm{Cr}$ alloys containing 3-18 at.\% $\mathrm{Cr}$ neutron irradiated at $563 \mathrm{~K}$ to $1.82 \mathrm{dpa}$. $\alpha$ ' precipitation was revealed for irradiated alloys containing $\geq 9$ at. $\% \mathrm{Cr}$ (Fig. 11 (b)), whereas $\alpha$ ' precipitates were not observed in unirradiated alloys (uniform distribution of Cr) (Fig. 11 (a)) [50]. Both the $\mathrm{Cr}$ concentration dependence of $\alpha^{\prime}$ precipitation and the measured matrix compositions in the irradiated alloys are in agreement with recently published $\mathrm{Fe}-\mathrm{Cr}$ phase diagrams [51]. The phase 
boundary between the $\alpha$ phase ( $\mathrm{Cr}$ in Fe solid solution) and the two-phase region $\alpha+\alpha$, where $\alpha^{\prime}$ is the Cr-rich phase, is close to 9 at. $\%$ at $\sim 290{ }^{\circ} \mathrm{C}$ (the $\mathrm{Cr}$ solubility limit is $\sim 9$ at. $\%$ at this temperature). Therefore, the formation of $\alpha^{\prime}$ precipitates ( $\mathrm{Cr}$ concentration $\sim 85-87$ at. $\%$ ) in the irradiated $\mathrm{Fe}-\mathrm{Cr}$ alloys may be the result of a radiation-enhanced mechanism rather than a radiation-induced one. The finely dispersed $\alpha^{\prime}$ precipitates were observed in grain interiors and did not appear to be associated with radiation-induced defects such as dislocation loops, which is consistent with a radiation-accelerated diffusion mechanism. The precipitate number density is on the order of $10^{22} / \mathrm{m}^{3}$ in $9 \mathrm{Cr}$ alloy, $10^{23} / \mathrm{m}^{3}$ in $12 \mathrm{Cr}$ alloy, and $10^{24} / \mathrm{m}^{3}$ in $15 \mathrm{Cr}$ and $18 \mathrm{Cr}$ alloys [50]. The average precipitate diameter is on the order of 1-2 $\mathrm{nm}$ in all these alloys. It was evident that the number density of precipitates significantly increases with increasing $\mathrm{Cr}$ concentration whereas the average precipitate size decreases. This phenomenon is ascribed to the increasing driving force for $\alpha$ ' nucleation with the increasing $\mathrm{Cr}$ concentration in the alloy.

Much larger $\alpha$ ' precipitates (10-15 nm in size) were identified in $12 \mathrm{Cr}$ and $18 \mathrm{Cr}$ alloys irradiated to $24.5 \mathrm{dpa}$ at $400{ }^{\circ} \mathrm{C}$, which is consistent with a lower nucleation rate and possibly coarsening at higher temperatures [18]. Nanometer-scale $\alpha^{\prime}$ precipitates were present in $\mathrm{Fe}-\mathrm{Cr}$ alloys $(9-12 \% \mathrm{Cr})$ neutron-irradiated at $300{ }^{\circ} \mathrm{C}$ up to $0.6 \mathrm{dpa}$ [52]. Transmission electron microscopy (TEM) examination of irradiated $\mathrm{Fe}-9 \mathrm{Cr}$ at 370 and $403{ }^{\circ} \mathrm{C}$ did not observe $\alpha$ ' precipitates, suggesting that at these higher temperatures the $\mathrm{Cr}$ concentration is within the solubility limit [53]. The $\alpha$ ' precipitates in the matrix contributes to hardening and embrittlement [54].

Homogeneously distributed $\mathrm{Si}-\mathrm{P}-\mathrm{Ni}-\mathrm{Cr}$ enriched precipitates are also observed in the matrix in the $\mathrm{Fe}-15 \mathrm{Cr}$ and $\mathrm{Fe}-18 \mathrm{Cr}$ alloys neutron irradiated at $290{ }^{\circ} \mathrm{C}$ to $1.82 \mathrm{dpa}$ (Fig. 12(c)) [50]. In the irradiated $\mathrm{Fe}-15 \mathrm{Cr}$ alloy, the average composition of the $\mathrm{Si}-\mathrm{P}-\mathrm{Ni}-\mathrm{Cr}$ enriched 
precipitates is $\sim 25.0$ at. $\% \mathrm{Cr}, \sim 2.8$ at. $\% \mathrm{Si}, \sim 1.2$ at.\% $\mathrm{P}, \sim 4.7$ at.\% $\mathrm{Ni}$ [55]. The mean radius and number density of these precipitates was estimated to be $\sim 2.0 \mathrm{~nm}$ and $\sim 5.4 \times 10^{22} / \mathrm{m}^{3}$, respectively [55]. The number density of the $\mathrm{Si}-\mathrm{P}-\mathrm{Ni}-\mathrm{Cr}$ enriched precipitates is almost two orders of magnitude lower than that of the $\alpha^{\prime}$ precipitates. Because a significant thermodynamic driving force for precipitation of the cited impurities is absent due to the extremely low concentrations of $\mathrm{Si}, \mathrm{Ni}$ and $\mathrm{P}$ in the alloy, it is likely that a radiation-induced mechanism is operative in this case. Radiation-induced $\mathrm{Si}-\mathrm{P}-\mathrm{Ni}-\mathrm{Cr}$ enriched precipitates with comparable number densities and concentrations were reported in lower $\mathrm{Cr}$ ferritic steels [52].
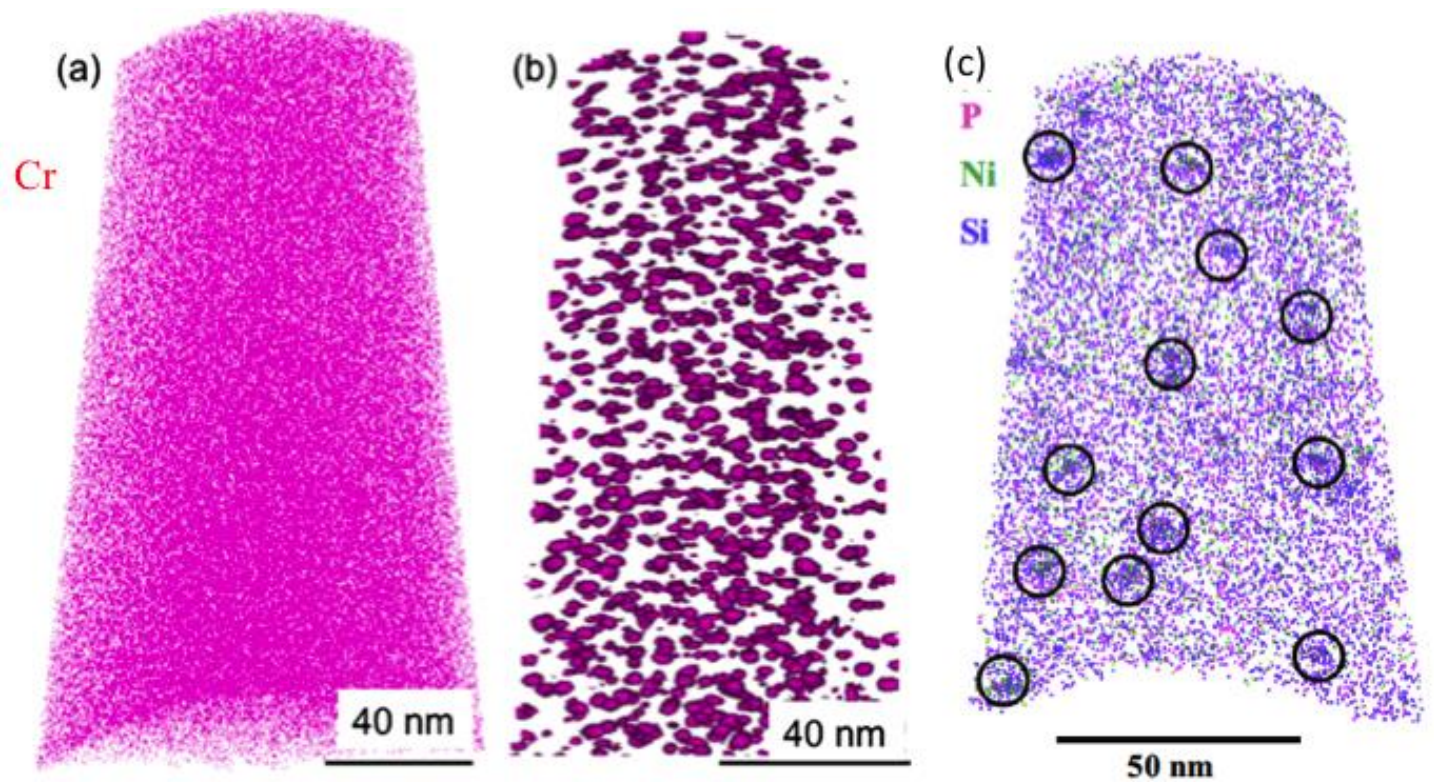

Fig. 11. Atom probe tomography 3D reconstructions of $\mathrm{Fe}-15$ at.\% $\mathrm{Cr}$ alloy from regions away from grain boundaries in the (a) as-received condition and (b) (c) neutron irradiated condition. $\mathrm{Cr}$ atoms are homogeneously distributed in (a). In (b), the Cr-enriched clusters ( $\alpha^{\prime}$ precipitates) are revealed by iso-concentration surfaces at 34 at.\% Cr. In (c), circled are clusters enriched in P, Si and Ni [54]. 


\subsection{Radiation-induced amorphization}

$\mathrm{SiC}$ is a potential candidate material for Generation IV reactors in addition to the ferritic and austenitic steels described previously. It is considered promising because of its high radiation resistance, excellent mechanical properties, low neutron-induced activation, low decay heat, chemical inertness at high temperatures, and availability in various forms including high fracture toughness composites.

Irradiation-induced amorphization has been widely reported in $\mathrm{SiC}$. Most of the $\mathrm{SiC}$ amorphization studies have used low-energy ion-beams, with a few using high-energy electrons. It was observed that at low temperatures there is a temperature-independent amorphization dose, whereas above a certain temperature the damage level required to amorphize $\mathrm{SiC}$ increases rapidly [56]. In addition, there is a critical temperature above which amorphization appears impossible. This critical temperature has been reported to range between $20^{\circ} \mathrm{C}$ and $70^{\circ} \mathrm{C}$ for electrons, $150^{\circ} \mathrm{C}$ for $\mathrm{Si}$ ions and $\sim 220^{\circ} \mathrm{C}$ for Xe ions, all with similar damage rates of $\sim 1 \times 10^{-3}$ dpa/s [57-59]. Snead et al. studied neutron irradiation of high purity chemically vapor deposited (CVD) cubic $\mathrm{SiC}$ at $\sim 60^{\circ} \mathrm{C}$ to a total fast neutron fluence of $2.6 \times 10^{25} \mathrm{n} / \mathrm{m}^{2}$ [56]. Amorphization occurred in the material as evidenced by TEM, electron diffraction and X-ray diffraction data. After amorphization, the density was reduced by $\sim 10.8 \%$. The hardness obtained from nanoindentation was $65 \%$ of the unirradiated value, and the elastic moduli was 58\% [56]. Vickers hardness of the amorphized $\mathrm{SiC}$ was $\sim 76 \%$ of that of the unirradiated material. An increase in the indentation fracture toughness from 2.5 to $3.2 \mathrm{MPa} / \mathrm{m}^{1 / 2}$ was observed upon $\mathrm{SiC}$ amorphization. Using measured values of thermal conductivity for irradiated crystalline $\mathrm{SiC}$ and the amorphized $\mathrm{SiC}$, the critical temperature for amorphization of $\mathrm{SiC}$ at $2.6 \mathrm{dpa}$ and $2.6 \times 10^{25}$ $\mathrm{n} / \mathrm{m}^{2}$, above which amorphization is not possible, is estimated to be $\sim 125^{\circ} \mathrm{C}$ [56]. 
There are two irradiation-induced amorphization mechanisms for ceramics: homogeneous amorphization and heterogeneous amorphization. Homogeneous amorphization involves a collapse of the whole lattice at crystalline-to-amorphous (c-a) transition point due to defect accumulation, whereas heterogeneous amorphization occurs by nucleation and growth of amorphous zones progressively during irradiation [60]. Both homogeneous [61] and heterogeneous amorphizations [62, 63] have been proposed to be the dominant mechanism during irradiation-induced amorphization in SiC. Different irradiation particles may also induce different amorphization mechanisms. In addition, the key defects that drive amorphization in SiC have been investigated. There has been disagreement regarding whether Frenkel pairs or antisites are more important [64-66]. Jin et al. studied irradiation-induced amorphization in SiC by $1 \mathrm{MeV}$ neutrons using molecular dynamics simulations [60]. The c-a transition occurred at 0.27 dpa by a structure relaxation of the whole lattice. Fast neutrons produced many displacement spikes with unsaturated coordinated atoms. The two-coordinated Si atoms are crucial in defect accumulation and subsequent amorphization. Two types of defects are present, including displaced-atominduced (D-type) defects and vacancy-induced (V-type) defects. The D-type defects tend to form clusters and promote the formation of C Frenkel pairs after $0.13 \mathrm{dpa}$. The V-type defects enhance the driving force of c-a transition and finally trigger amorphization at high concentration.

\section{Advances in characterization of defects in irradiated materials}

In recent years, advances in technology have increased utilization of existing techniques and new techniques have been developed to help characterize irradiation defects. Dramatic advances in characterization capabilities have been made in the past years, which enable microstructural and chemical 3D characterization of specimens at atomic scale with high 
quantitative precision and high data collection rates. The techniques that are being implemented in the nuclear materials field include but are not limited to in situ and ex situ TEM, focused ion beam/scanning electron microscopy (FIB/SEM), atom probe tomography (APT), micro x-ray diffraction (XRD), positron annihilation spectroscopy (PAS), synchrotron techniques, and smallangle neutron scattering (SANS). These experimental techniques, which are able to detect irradiation-induced microstructural changes at micro- and nano-scale, play a critical role in validation of models. These models are needed to provide validated microstructure-property relationships that enable predictions of long-term materials behavior. However, due to the complexity of the problem and strength and weaknesses of the individual techniques, one has to use a combination of two or more techniques to obtain a more complete picture.

Transmission electron microscopy has been widely used for structural characterization of the irradiated microstructures and is one of the primary techniques used for characterization of nano-sized defects in structural materials. These microscopes have been used for decades to characterize dislocations (size, density, type), voids, bubbles, and precipitates in materials, as well as grain sizes on the nano scale and misorientation of grain boundaries. In addition to imaging, semi-quantitative chemical compositions can be obtained using characteristic x-rays due to electron beam excitation. Electron diffraction provides structural information such as phases and ordering of the structure (amorphous versus crystalline). Improvements over the decades in TEM probe size, collection efficiency, and probe currents have greatly improved capability of TEM in characterization of materials. Figure 12 shows high-resolution TEM micrographs of irradiated $\mathrm{SiC}$ that were used to calculate irradiation-induced volume swelling [67]. 

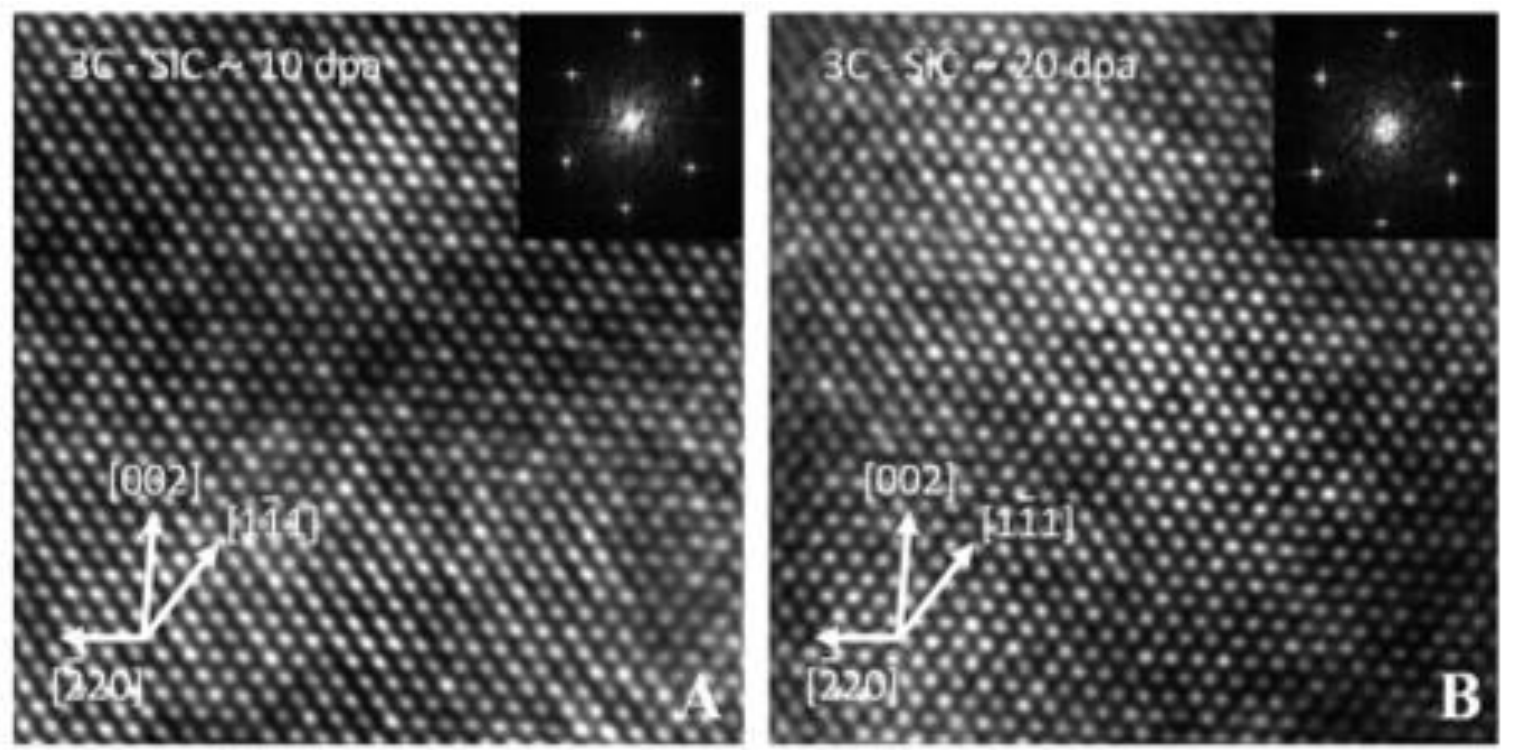

Fig. 12. High resolution micrographs of $\mathrm{SiC}$ irradiated to a) $10 \mathrm{dpa}$ and b) $20 \mathrm{dpa}$ [67].

Though not necessarily new advancements in TEM technology, new techniques have been implemented on irradiated materials in the TEM. These techniques include precession electron diffraction (PED) using the ASTAR system, low-Z chemical quantification using electron energy loss spectroscopy (EELS), and high resolution imaging of defects on the atomic scale using aberration corrected microscopes. The Topspin ASTAR ${ }^{\mathrm{TM}}$ system is an accessory to the TEM that provides automatic crystallographic indexing and orientation/phase mapping in TEM at nanometer scale. For irradiated materials, grain orientation and size are important for understanding defect microstructure. Grain boundaries can act as sinks for certain defects, which can reduce or accumulate irradiation defects. Grain boundary misorientation can affect defect concentrations as well. The electron energy loss spectroscopy is complementary to energy dispersive $\mathrm{x}$-ray spectroscopy (EDS). In both techniques, semi-quantitative chemical compositions can be obtained. Another technique that is in the beginning stages of implementation in nuclear materials field is electron tomography (ET). 
Electron tomography in the transmission and scanning transmission electron microscope (TEM/STEM) has the advantage of simultaneously detecting a variety of signals, thus providing Z-contrast and bright field images, quantitative EELS and EDS point and line data, and EDS spectrum and energy filtered TEM (EFTEM) images. EDS and EFTEM can provide detailed initial information on chemical segregation at interfaces, composition of precipitates, crystallographic space groups, and lattice parameter information. It is sensitive to changes in chemistry but the extent of sensitivity depends on spatial resolution and magnification.

This limitation can be eliminated by combining these techniques with the atom probe tomography (APT) technique using a local-electrode atom probe (LEAP) instrument that provides detailed compositional information. Atom probe tomography is a destructive technique that uses controlled field evaporation of atoms from the needle shaped specimen surface. Upon application of a high electrical field, breakage of surface-atom bonds and field evaporation lead to removal of atoms from the specimen; the evaporated atoms are ionized, and the ions are accelerated toward and finally hit a position-sensitive detector, which records position of each individual ion and determines their chemical identity using time-of-flight mass spectrometry. APT provides information on elemental composition of the specimen, 3D visualization of distribution of atoms, morphology and size of phases, composition of phases, and solute distribution across interfaces, at grain boundaries and along dislocations. Figure 13 shows a stable nanocluster population in oxide dispersion-strengthened steel irradiated to $100 \mathrm{dpa}$ at 600 ${ }^{\circ} \mathrm{C}[68]$. The two described techniques (ET, APT) are complementary because of the differences in analyzed volume, and the ease in evaluation of data quality and post-examination data processing. ET is capable of characterizing entire specimen and providing information on structure and morphology of the material and initial chemical information, while APT 
characterizes smaller specimen volume and provides detailed 3D chemical information at atomic level. In the last few years, application fields of ET and APT have rapidly diversified and both techniques have been implemented in the field of nuclear materials science.
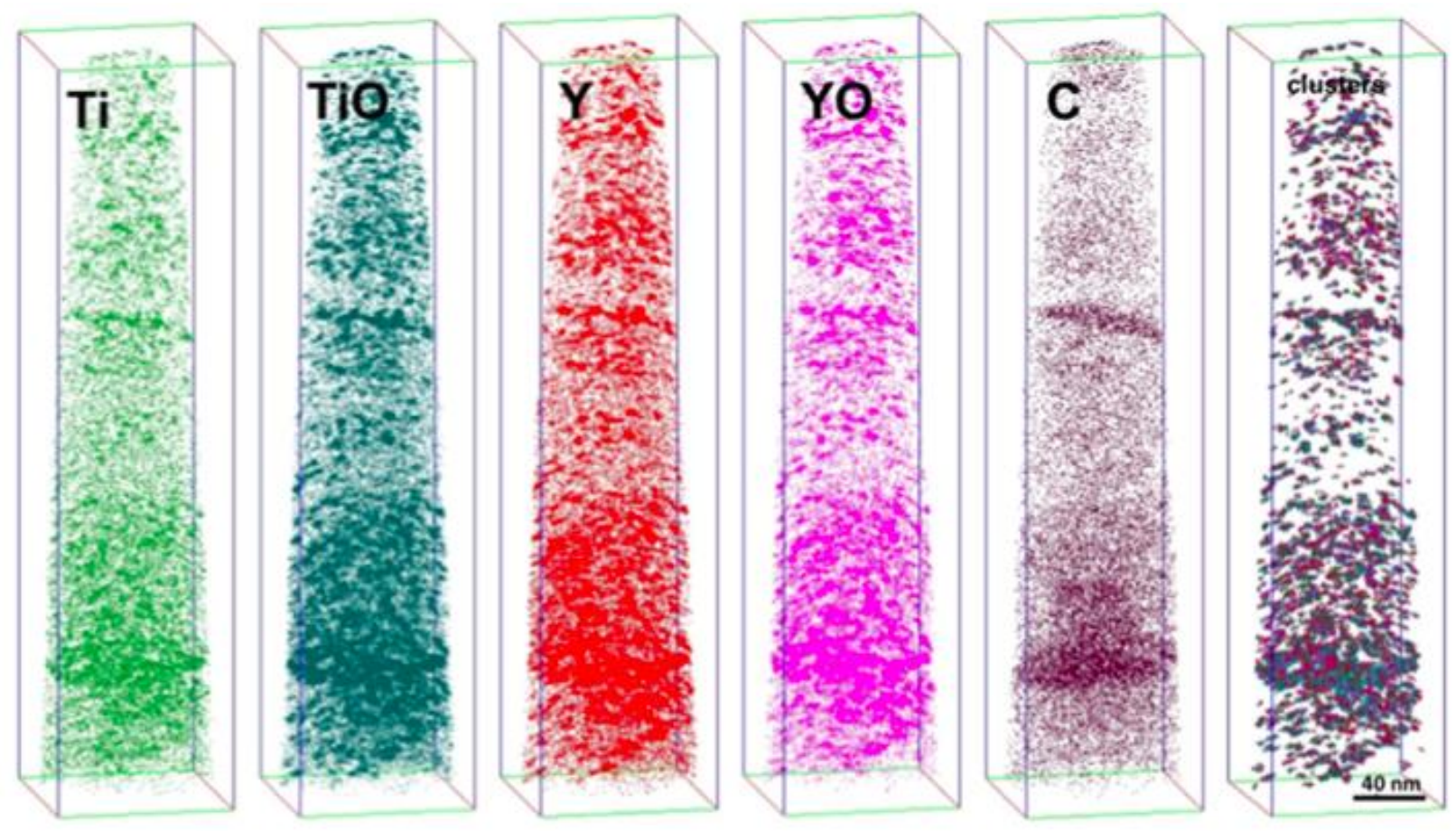

Fig. 13. Atom probe data set for ODS $14 \mathrm{YWT}$ ferritic steel irradiated to $100 \mathrm{dpa}$ at $600{ }^{\circ} \mathrm{C}$. The data set shows Ti, TiO, Y, YO, and C maps from the same sample separately, and "clusters", where all cluster components are shown together excluding the matrix. Grain boundaries are visible in two places in the sample, decorated by carbon and clusters [68].

Small-angle neutron scattering technique can characterize the size distribution of small defect-solute clusters formed in a variety of alloys during irradiation. The lower detection limit of the clusters is about $0.5 \mathrm{~nm}$ in radius. In this technique, scattering cross-section in a saturated magnetic field is applied to the sample while separating the nuclear and magnetic contributions 
from the anisotropy induced by the magnetic field [69]. The scattering cross-section of a control sample (unirradiated counterpart material) is subtracted during calculation of the size distribution, which is performed by solving an inverse problem. Similar information may be obtained using APT and SANS analyses, since both methods provide information on size, volume fraction, and composition of clusters.

Positron annihilation spectroscopy (PAS) is an excellent technique for investigating vacancy-clusters and vacancy-solute complexes behavior during irradiation since positrons are very sensitive to these types of defects. These defects are important for the formation of the features responsible for hardening. In this technique, positrons are applied as a probe and positrons are trapped by defects with electron densities different from the bulk materials. These defects can be vacancies, vacancy clusters, interfaces, second phase particles, dislocations, etc. [69]. Positrons annihilate with a different probability in the defects as compared to the bulk material because of the difference in positron affinity to different atomic species [69]. The advantage of the technique lies in its non-destructiveness, self-seeking nature, and ability to find small defects $(>0.1 \mathrm{~nm})$ even in low concentrations (>1ppm) [69]. PAS can provide information to complete the observations made in TEM. These two techniques are considered to be fully complementary in characterization of irradiation defects. Figure 14 shows the complementary nature of the APT, SAND, TEM, and PAS techniques. 


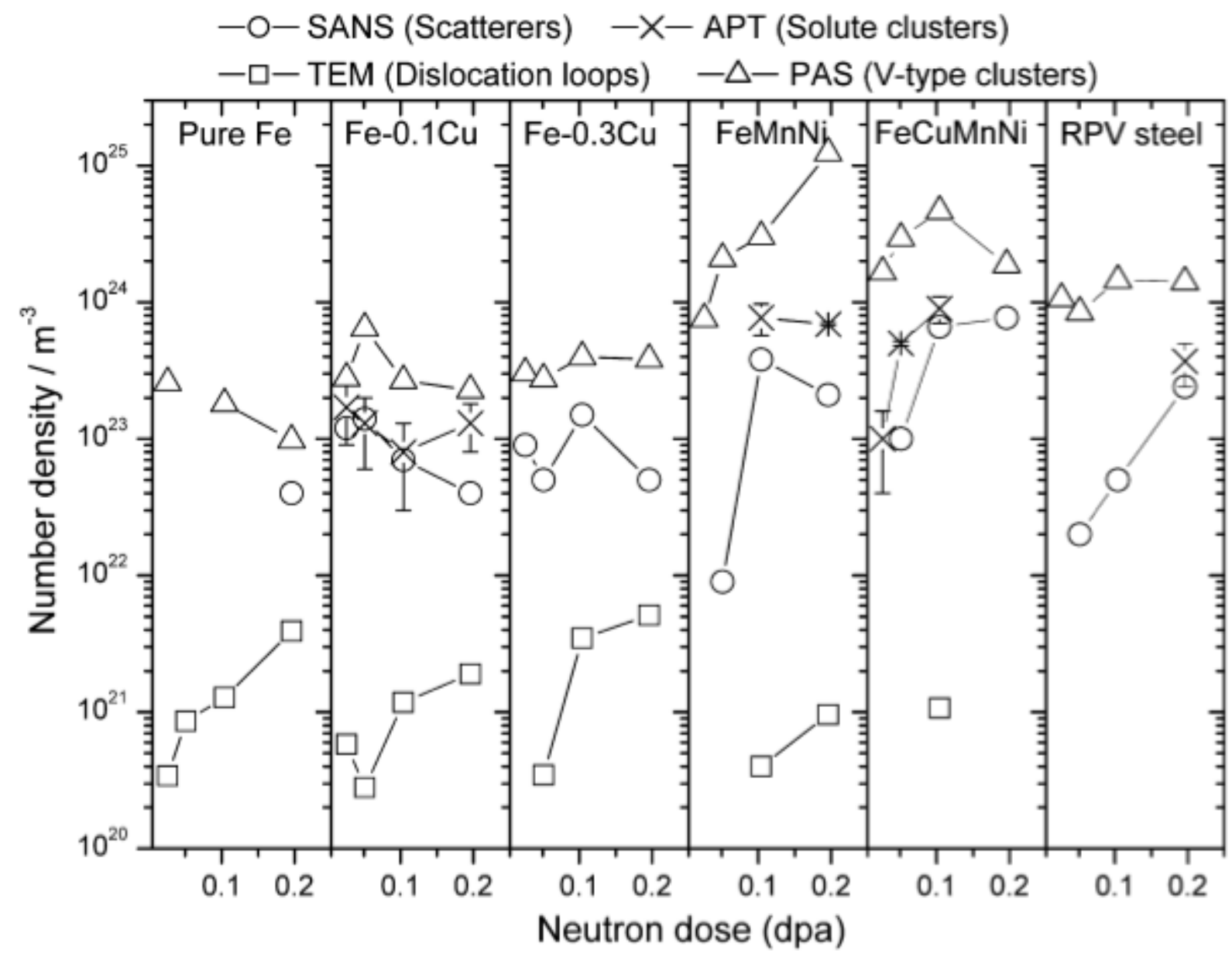

Fig. 14. Number density of radiation-induced damage as a function of dose obtained using SANS, APT, TEM, and PAS in ferritic alloys and a reactor pressure vessel (RPV) steel [69].

\section{Mesoscale modeling of radiation damage}

Complementary to experiments, computer modeling plays a critical role in understanding and predicting the materials degradation under irradiation. Radiation-induced microstructural evolution is an inherent multiscale process ranging from atomistic to macroscopic level. The length scale spans about 10 orders of magnitude ranging from angstrom-level point defects to meter-level reactor components. The time scale spans about 22 orders of magnitude ranging from picosecond-scale cascade damage to decade-level component aging [70]. To model this complex 
process, a multiscale approach with information passing between different scales is required, as shown in Fig. 15 [71, 72]. At the atomistic level, ab initio density functional theory and molecular dynamics are two widely used methods for studying radiation damage. Atomistic modeling can provide defect formation energies, defect binding energies, defect migration barriers and mobilities, cascade damage efficiency, interaction mechanisms between small defects and extended defects. The defect energetics, kinetics, and controlling mechanisms obtained from atomistic modeling can be used as inputs for modeling the microstructural evolution at the mesoscale. The mesoscale methods include kinetic Monte Carlo, phase field, kinetic rate theory and its extension cluster dynamics. These methods have been widely used to study void and dislocation loop growth [73, 74], void swelling [74], radiation-induced/enhanced precipitation [70, 75, 76], radiation-induced segregation [44], radiation-induced formation of patterned microstructures [77], etc.

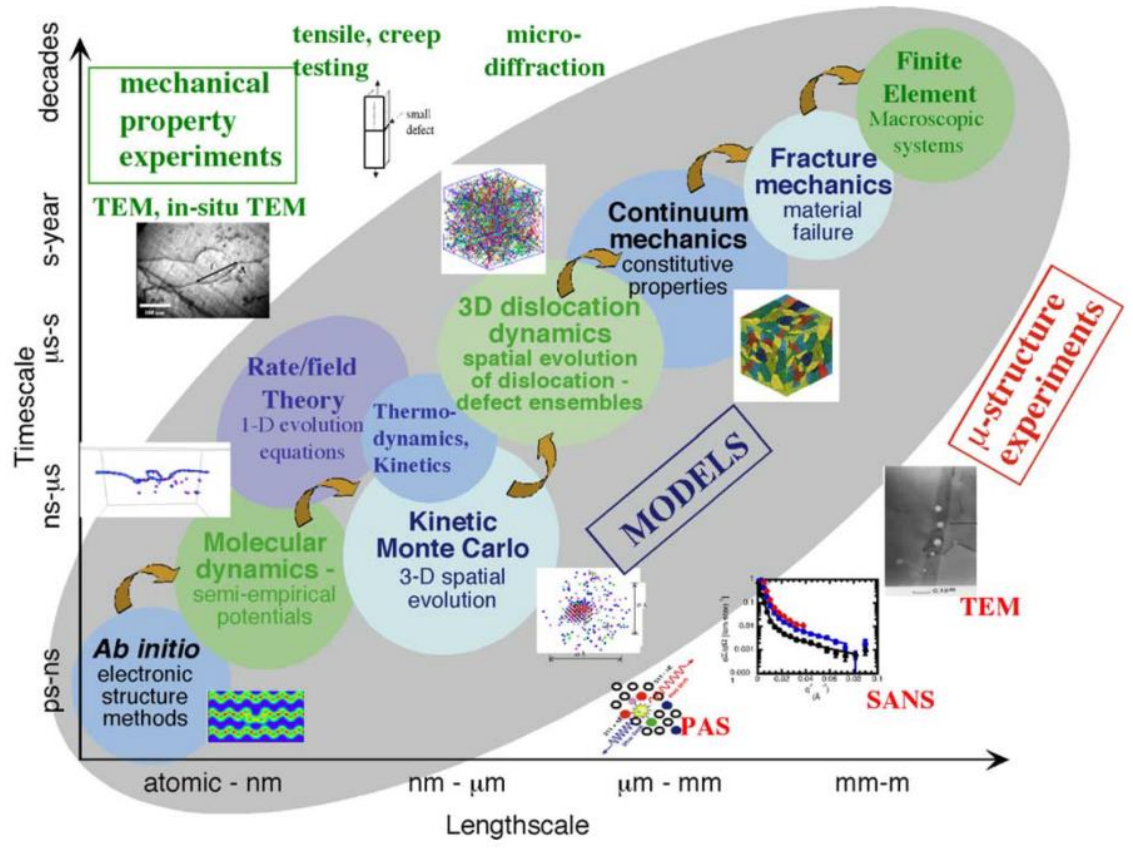


Figure. 15. Schematic illustration of science-based multiscale modeling of radiation effects in materials and associated experimental techniques [70].

The radiation-induced microstructural evolution modifies many physical properties of materials. Among them, the change of mechanical properties is of particular importance to structural materials. For instance, voids, loops, and precipitates are obstacles for dislocation motion. In turn, the yield strength increases (radiation hardening) and the strain to failure decreases (radiation embrittlement). The relation between microstructures and mechanical properties can be predicted by dislocation dynamics [78] or some dispersed barrier models such as Orowan strengthening model [79]. The predicted irradiation hardening and embrittlement based on microstructures can then be an input for finite element based continuum modeling to predict the mechanical properties at the component level. At all scales, different types of experimental validation should be used to calibrate or validate the modeling prediction. Different from the conventional empirical fitting that has limited predictive power, this multiscale modeling strategy is a science-based approach to correlate the physical properties with microstructures so that the modeling results may be extrapolated to the conditions out of the experimental validation range. For example, in many accelerated irradiation-testing experiments the dose rate is much higher than that in reality. The science-based multiscale modeling has the potential to extrapolate the results from high dose rate to low dose rate. In this multiscale approach, the mesoscale modeling of the kinetic evolution of microstructures is of particular importance because it serves as a bridge to connect the atomistic mechanisms with continuum results and experimentally accessible properties. Here we briefly review a few mesoscale 
modeling methods and their recent advancements in modeling radiation-induced microstructural evolution in structural materials.

\subsection{Cluster dynamics modeling of void and dislocation loop growth}

The formation of voids and dislocation loops under irradiation results from the accumulation of point defects (vacancies and interstitials) and their small clusters. These small defects are directly created in collision cascades and they have various fates during their kinetic evolution. They may be lost to sinks such as dislocations, grain boundaries, and free surfaces, be annihilated when they meet defects of opposite type, and grow to voids or dislocation loops when they join defects of like type. Cluster dynamics (CD), which is based on the mean-field kinetic rate theory (RT), is widely used to model these processes. In CD, defects and microstructural features are assumed to be homogenously distributed in materials so that they are represented by the average densities without a spatial correlation. The defect-defect reaction and defect-microstructure interaction are determined by isotropic rate constants and sink strength. In the classical RT method, typically only Frenkel pairs (interstitials and vacancies) are produced (which represents $1 \mathrm{MeV}$ electron irradiation), only the average sizes of voids and loops are modeled, and the densities of voids and loops are pre-assumed at fixed values (no nucleation). $\mathrm{CD}$ does not have these limitations so that it can model defect clusters directly produced from dense cascades under neutron or heavy-ion irradiation, nucleation of voids and loops, and their size distributions during growth. As seen in Fig. 16 (a), the densities and size distributions of defect clusters under radiation can be obtained from CD [80]. In addition, CD also can model void swelling by calculating the number of vacancies accumulated in vacancy clusters or voids [73]. One advantage of $\mathrm{CD}$ is that it can reach high irradiation doses with low computational cost 
due to its mean-field approximation. This ability is important for modeling the radiation effects in Gen IV structural materials because typically they may receive a few hundred dpa during their lifetime, as shown in Fig. 1. CD also can handle the fast diffusion of interstitials and slow diffusion of vacancies simultaneously. Moreover, the defect densities in CD are essentially unlimited. This is distinct from many spatially resolved methods in which the minimum defect density is one defect per domain volume [73].
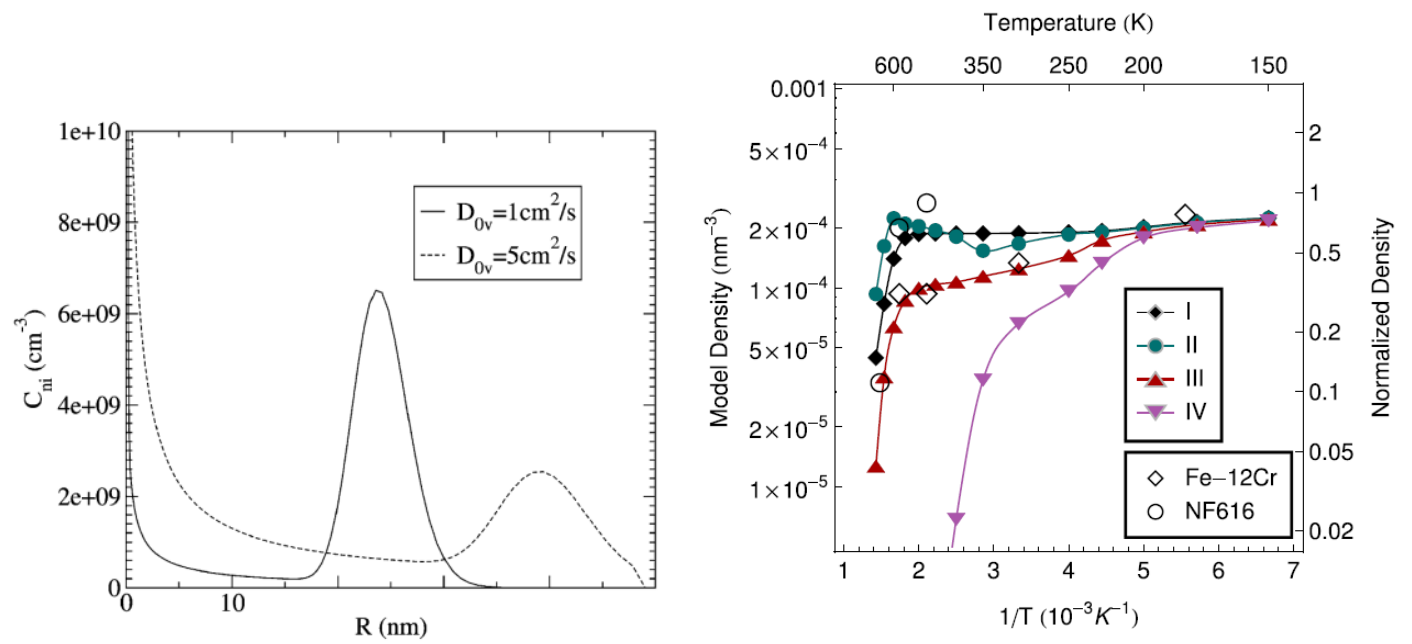

Fig. 16. Cluster dynamics modeling of radiation damage in materials. (a) A typical interstitial cluster size distribution obtained from cluster dynamics modeling [80]. (b) Comparison of the saturated interstitial cluster density at different temperatures in Fe-12Cr alloys and NF616 steels between cluster dynamics modeling and experiments [81].

In general CD does not have a spatial resolution so that defects and sinks are assumed to distribute homogenously in space. In neutron irradiation of bulk samples, the damage is homogenous (although the formation of local compositions through transmutation of atoms is not) so that the non-spatially resolved $\mathrm{CD}$ is suitable for modeling the damage evolution. 
However, in in situ heavy-ion irradiation of TEM samples, the irradiation dose is a function of the depth from sample surface. In addition, the large surface sink effects from the thin TEM foil must be taken into account. Considering these factors, Xu et al. [82] used a 1-D spatially resolved $\mathrm{CD}$ model to model the damage evolution in molybdenum under $1 \mathrm{MeV} \mathrm{Kr}$ irradiation in an Intermediate Voltage Electron Microscope (IVEM). Using a subset of the defect cluster evolution kinetics in experiments, they parameterized the interstitial cluster mobilities in their CD model. After the model had been calibrated, it successfully predicted the areal density of TEM-visible interstitial clusters at different fluence rates, fluences, and foil thickness at $80{ }^{\circ} \mathrm{C}$.

Recently, a spatially-resolved model has also been applied to study the $1 \mathrm{MeV} \mathrm{Kr}$ irradiation in Fe-Cr F-M alloys and the commercial NF616 steels [81]. The in situ irradiation experiments showed that the interstitial cluster density saturates at around $10 \mathrm{dpa}$ and the saturation is insensitive to temperature when the temperature is below $300{ }^{\circ} \mathrm{C}[83,84]$. In addition, interstitial clusters were found to hop for a few tens of nanometers and then remain immobile for some time when the irradiation beam is on. However, the clusters are immobile when the beam is off. It is likely that impurities trapped in the clusters make the clusters immobile, while the irradiation may de-trap the impurities so that the clusters become mobile until they are trapped by impurities again [85].

Kohnert et al. [81] showed that using a conventional CD model in which defect and cluster diffusion are thermally activated, the interstitial cluster density increases with the inverse of temperature and the temperature-insensitive behavior below $300{ }^{\circ} \mathrm{C}$ observed in experiments cannot be captured. However, if a non-thermal diffusion term is added to the cluster diffusivity to account for the beam-assisted athermal hops of clusters, the experimental observed trend can be well captured in CD models, as seen in Figure 16 (b). 
Although CD is a powerful tool for modeling microstructural evolution under irradiation, it has some inherent limitations. As mentioned earlier, CD typically assumes that sink strength and rate constants are isotropic. As a result, the morphologies of defect clusters are limited to ideal geometries such as spheres and disks. In addition, the spatial correlation between clusters cannot be automatically captured in CD without assumptions. Such limitations can be solved in some spatially resolved methods such as kinetic Monte Carlo and phase field, as discussed in the next two subsections.

\subsection{Kinetic Monte Carlo modeling of phase precipitation in alloys}

Radiation can cause the precipitation of new phases in alloys. As discussed earlier, the precipitation can be either a radiation-enhanced precipitation in which the radiation-enhanced diffusion accelerates the precipitation kinetics, or a radiation-induced precipitation in which radiation can cause the precipitation of new phases in unsaturated alloys. The Kinetic Monte Carlo (KMC) method [70] has been widely used to model the precipitation process. KMC is a stochastic method and accepts transition events based on the probability distributions of known events. The probability (or rate) for a given defect/solute-jumping event is based on its activation energy. The KMC with atomic lattice resolution is called atomic $\mathrm{KMC}$ (AKMC) or lattice $\mathrm{KMC}$ (LKMC). KMC can capture the 3-D spatial correlation of defects. For example, the cascade debris from molecular dynamics simulations can be directly input to AKMC for further aging [70]. One advantage of $\mathrm{KMC}$ is that it can take into account the local environment dependence of solute migration barriers. The environment-dependent migration barrier can be estimated in a simple approach from saddle energy, initial energy, and final energy [70]. These energies may be calculated from $a b$ initio density functional theory or empirical potential calculations. The ability 
of modeling environment-dependent defect/solute diffusivities is important for studying the precipitation in concentrated alloys, which are usually true for Gen IV structural materials. Since the computational cost of AKMC is high, rigid lattice model is often used to reach long timescale. Typically, KMC uses vacancy exchange to model solute precipitation and the contribution from interstitials is usually ignored.

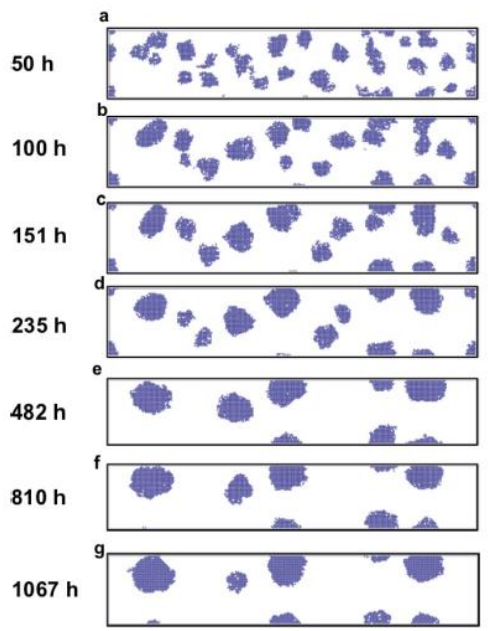

(a)

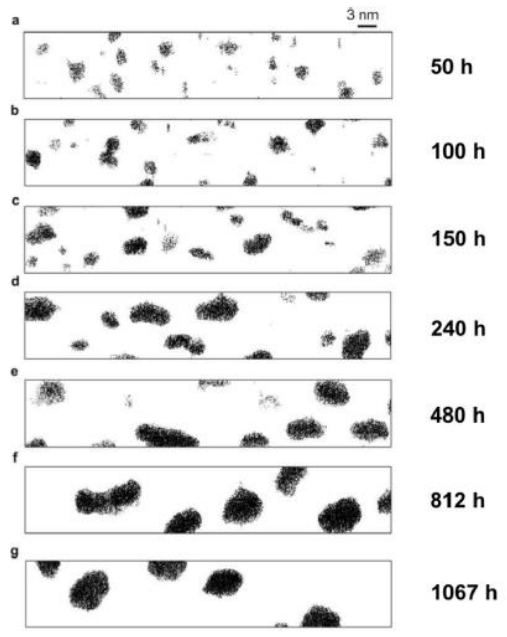

(b)

Fig. 17. Comparison between (a) KMC modeling and (b) 3D atom probe experiments of Cr-rich precipitation in $\mathrm{Fe}-20 \% \mathrm{Cr}$ at $500{ }^{\circ} \mathrm{C}$ [86].

KMC has been widely used to study the radiation-enhanced $\mathrm{Cu}$ precipitation in $\mathrm{Fe}-\mathrm{Cu}$ dilute alloys. Copper has very low solubility in $\alpha$-Fe and the precipitation of $\mathrm{Cu}$-rich clusters may affect the mechanical integrity of reactor pressure vessel steels during the life extension of current reactors. The topic of $\mathrm{KMC}$ modeling of $\mathrm{Cu}$ precipitation in $\mathrm{Fe}$ has been reviewed comprehensively by Vincent et al. [75] and Becquart et al. [70]. However, the KMC modeling of the radiation-enhanced precipitation of $\mathrm{Cr}$-rich $\alpha^{\prime}$ phase in $\mathrm{Fe}-\mathrm{Cr}$ concentrated alloys is very limited. Recently, researchers have used AKMC to model $\alpha^{\prime}$ phase precipitation during thermal aging (no irradiation) in high-Cr Fe-Cr alloys [86, 87]. Modeling the precipitation of $\alpha$ ' phase 
precipitation of $\mathrm{Fe}-\mathrm{Cr}$ systems is challenging because the sign of the heat of mixing changes at 9\% $-12 \% \mathrm{Cr}$ range due to the magnetic effects [86]. In Martinez's work [86], solute diffusion is mediated by vacancy exchange in a rigid lattice with pair interaction. The pair interaction was parameterized with $a b$ initio calculation results that include the magnetic effects. In addition, the local environment and temperature effects on migration barriers are also taken into account in the diffusion model. The authors demonstrated that their ab initio + KMC modeling has very good agreement with experiments, as seen in Fig. 17. The average size and density of precipitates also agree well with those in experiments (not shown). The ab initio based parameterization for KMC modeling also gives better results than that based on empirical potential [87] because the latter cannot take the magnetic effects into account.

\subsection{Phase field modeling of patterned structure formation under irradiation}

In addition to KMC, phase field (PF) method $[88,89]$ is another spatially resolved mesocale modeling method for studying the microstructural evolution. PF uses a set of field variables to describe the microstructures. The field variables can be either conserved (e.g., the alloy nominal composition) or non-conserved (e.g., order parameter). The kinetic evolution of conserved variables is described by the Cahn-Hilliard equation [90] and that of the nonconserved variables is describe by the Allen-Cahn equation [91]. The evolution of these field variables drives the system to the thermodynamic equilibrium. The interfaces in PF are assumed to be diffuse, i.e., the corresponding field variable changes smoothly from 0 to 1 . PF also can take anisotropic material properties such as interfacial energy, elasticity and diffusivity into account conveniently. In conventional PF modeling the time and length scales have reduced units so that the modeling results are qualitative rather than quantitative. As discussed in Bellon's 
recent review paper [89], the phenomenological coefficients in conventional PF modeling can be correlated with realistic interface energy and interface width so that real time and length scales can be used. Recently, the phase field modeling software, MARMOT [92], has been developed by Idaho National Laboratory aiming at using quantitative PF to model the microstructural evolution and physical property change in nuclear materials. MARMOT is based on the MOOSE framework [93] and uses finite element method to solve coupled phase field equations. MARMOT has both mesh and time adaptivity, can model 1D to 3D problems, and is highly parallel. In addition, MARMOT can easily couple PF with solid mechanics and heat conduction to study the coevolution of microstructures and material physical properties [94-96].

Hu et al. [77] used PF method to study the effects of 1-D interstitial diffusion on void superlattice formation under irradiation in a 2D domain. Under high-dose irradiation, void superlattices have been observed in many metals and alloys [97]. To improve the efficiency of modeling of interstitials and vacancies concurrently, 1-D random walk model based on first passage theory [98] was used to model fast interstitial diffusion, and Cahn-Hilliard [90] equation was used to describe 3-D isotropic vacancy diffusion. As seen in Fig. 18 (a), the PF modeling showed that voids can align along the 1-D interstitial diffusion direction due to the shadow effects proposed by Woo et al. [99]. They also concluded that the void lattice formation is sensitive to the mobility ratio between interstitials and vacancies and the dpa rate. Recently, Badillo et al. [100] used a combination of quantitative PF and discrete approach to study radiation induced segregation and precipitation in some model alloys with zero or positive heat of mixing. Both interstitial and vacancy clusters are modeled, and the ballistic mixing effect is also included in the model. They showed that their PF model can predict heterogeneous 
segregation of solute to defect clusters and homogenous precipitation in an unsaturated $\mathrm{A}_{8} \mathrm{~B}_{92}$ model alloys at high irradiation dose, as seen in Fig. 18 (b).
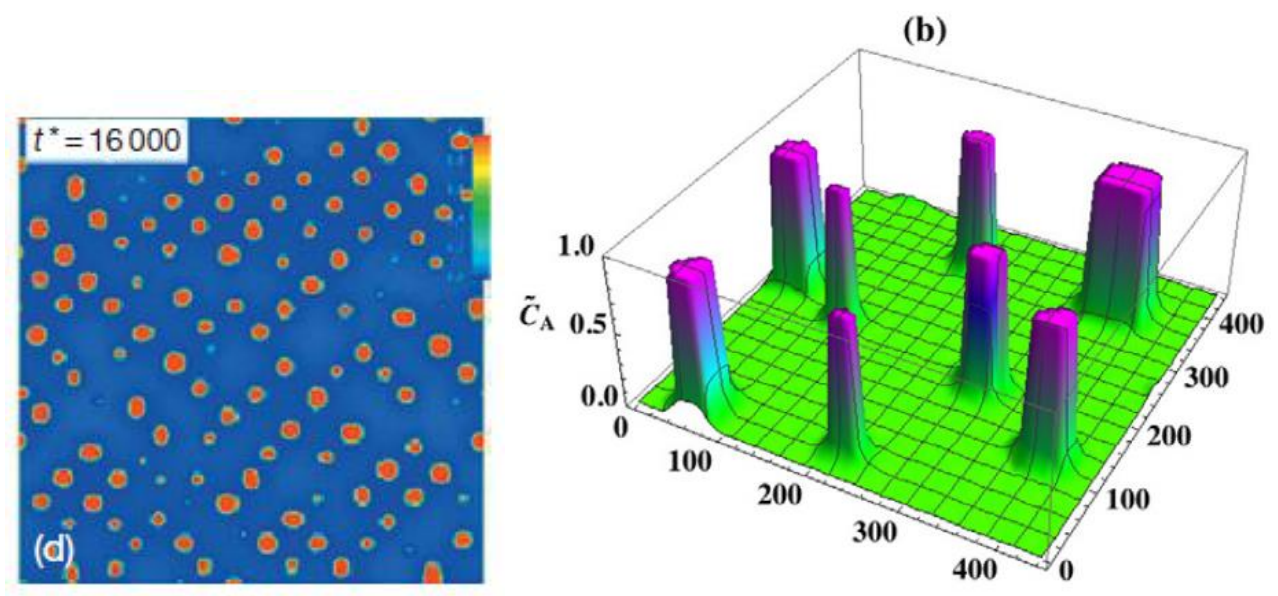

Fig. 18. (a) Phase field modeling of void lattice formation due to 1-D interstitial diffusion [77]. (b) Phase field modeling of radiation-induced homogenous precipitation in an unsaturated $\mathrm{A}_{8} \mathrm{~B}_{92}$ model alloy at 40 dpa [100].

\subsection{Rate theory modeling of irradiation induced segregation in alloys}

As discussed in Section 2.3, radiation can induce segregation of alloy elements at defect sinks such as grain boundaries [101]. Typically, RIS is a result of inverse Kirkendall (IK) effects in which the evolution of defect concentration field drives the evolution of alloy composition field. 1-D rate theory modeling $[44,101]$ is widely used to describe the coupled evolution between defect flux and composition flux. These rate theory models considered both vacancymediated and interstitial-mediated solute transport, as well as point defect recombination and defect loss to dislocations. At steady state, the solute segregation direction depends on the relative diffusivity of different species-defect coupled diffusion. In austenitic Fe-Cr-Ni alloys, 
the vacancy-mediated solute diffusion alone is sufficient in describing the RIS trend and the interstitial-mediated solute diffusion is usually assumed to have a neutral contribution to RIS [44]. However, in Fe-Cr F/M alloys, both interstitial- and vacancy-mediated diffusion should be considered [102].

Unlike the consistent RIS trend in austenitic steels, the $\mathrm{Cr}$ segregation in Fe-Cr F-M alloys can be either enriched or depleted [102]. Recently, Wharry et al. [103] showed that the Cr segregation in $\mathrm{Fe}-\mathrm{Cr}$ alloys depends on both $\mathrm{Cr}$ composition and temperature. The interstitial diffusion depends on $\mathrm{Cr}$ concentration and this composition-dependent interstitial diffusivity must be included in the RIS models. The interstitial and vacancy diffusivities have a crossover at about $600{ }^{\circ} \mathrm{C}$ (Fig. 19 (a)) so that the RIS direction depends on temperature. Taken these effects into account in RIS modeling, the model can correctly predict the RIS trend in Fe-Cr alloys (Fig. 19 (b)).
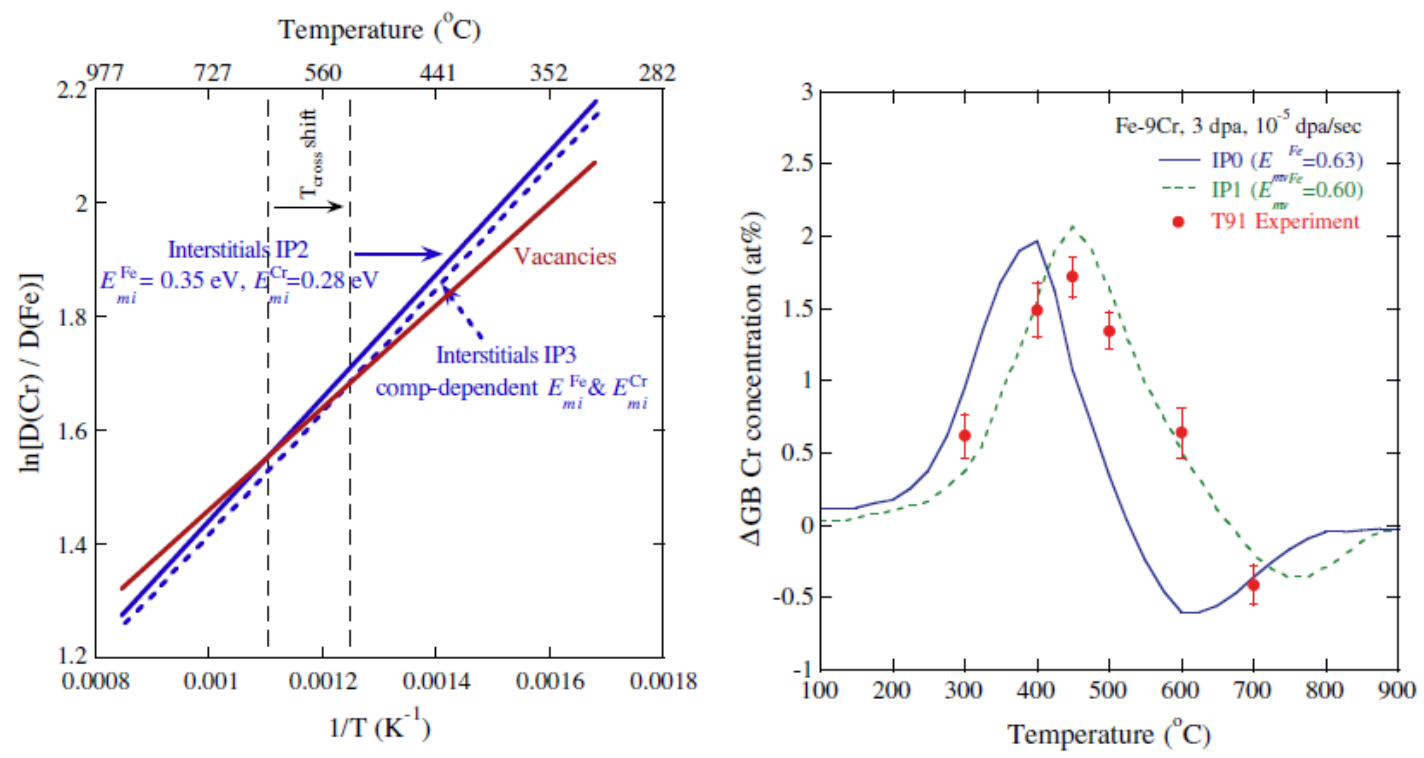

Fig. 19. (a) Arrhenius plots of interstitial and vacancy diffusivities for Fe-Cr alloys. Note the interstitial diffusivity is composition-dependent: solid blue line is for $\mathrm{Fe}-12 \% \mathrm{Cr}$, dashed blued 
line is for Fe-9\% Cr [103]. (b) Comparison of RIS model prediction and experimental results at different temperatures. Note that the negative segregation of $\mathrm{Cr}$ at $700{ }^{\circ} \mathrm{C}$ can be captured by the model [103].

\section{Summary}

Irradiation effects and microstructural changes in Generation IV reactor materials have been discussed in this chapter. The role of irradiation induced point, line, and volume defects in performance of steels has been discussed and radiation-induced segregation and precipitation mechanisms delineated. New characterization techniques recently deployed in nuclear materials field have been introduced and advantages and limitations of each technique have been provided.

Several mesoscale modeling methods were briefly discussed (CD, KMC, PF, RT) for modeling the microstructural evolution (loop and void growth, precipitation, formation of patterned structures, RIS) in structural materials during irradiation. Note that these methods can be complementary to each other. For example, CD can model precipitation [76], KMC also can model RIS [70], and PF can model precipitation and RIS as well [100]. Each method has advantages and disadvantages. Although these methods have been successfully applied to model many radiation effects in materials, they also have many limitations. For example, the modeling usually uses model materials and the complexities in realistic alloys (such as impurity trapping effects) have not been well modeled yet. The growth of intrinsic defect clusters, precipitation and RIS are typically modeled separately and their coupling effects have not been well addressed. In the future, these issues should be addressed in order to develop truly predictive models for modeling radiation effects in Generation IV structural materials. 


\section{Acknowledgements}

X.M.B gratefully acknowledges the support of the DOE Light Water Reactor Sustainability (LWRS) Program. This manuscript has been authored by Battelle Energy Alliance, LLC under Contract No. DE-AC07-05ID14517 with the U.S. Department of Energy. The United States Government retains and the publisher, by accepting the article for publication, acknowledges that the United States Government retains a nonexclusive, paid-up, irrevocable, world-wide license to publish or reproduce the published form of this manuscript, or allow others to do so, for United States Government purposes. 


\section{References:}

1. Zinkle S. J., in: NEA Workshop Proceedings, Karlsruhe, 4-6 June 2007.

2. Zinkle S. J., Busby J. T., Mater. Today 2009;12:12-19.

3. Konings R. J. M., "Comprehensive Nuclear Materials", Elsevier, Amsterdam, The Netherlands, 2012.

4. Norgett M. J., Robinson M. T., Torrens I. M., Nucl. Engr. and Design 1975;33:50

5. Was G.S., "Fundamentals of Radiaton Materials Science", Metals and Alloys, Springer, 2007

6. Klueh R.L., Harries D.R., "High-Chromium Ferritic and Martensitic Steels for Nuclear Applications", ASTM, 2001.

7. Yao B., Edwards D.J., Kurtz R.J., J. Nuc. Mater. 2013;434:402-410.

8. Yao Z., Jenkins M.L., Hernández-Mayoral M., Kirk M.A.,. Philos. Mag. 2010;90:46234634.

9. Dudarev S.L., Bullough R., Derlet P.M., Phys. Rev. Let. 2008;100;135503.

10. Matijasevic M., Almazouzi A., J. Nuc. Mater. 2008;377:147

11. Matijasevic M., Van Renterghem W., Almazouzi A., Acta Mater. 2009;57:1577-1585.

12. Nicol A.C., Jenkins M.L., Kirk A., Mater. Res. Soc. Symp. Proc. 2001;650:R1.3

13. Hoelzer D.T., Ebrahimi F., Mater. Res. Symp. Proc. 1995;373:57

14. Jenkins M.L., Yao Z., Hernández-Mayoral, Kirk M.A., J. Nuc. Mater. 2009;389:197-202.

15. Porollo S.I., Dvoriashin A.M., Vorobyew A.N., Konobeev Yu.V., J. Nuc. Mater. 1998;256:247-253.

16. Gelles D.S., J. Nuc. Mater. 1982;108-109:515-526.

17. Gelles D.S., J. Nuc. Mater. 1995;225:163-174. 
18. Konobeev Y.V., Dvoriashin A.M., Porollo S.I., Garner F.A., J. Nuc. Mater. 2006;355:124.

19. Malerba L., Caro A., Wallenius J., J. Nuc. Mater. 2008;382:112-125.

20. Edwards D.J., Simonen E.P., Garner F.A., Greenwood L.R., Oliver B.M., Bruemmer S.M., J. Nuc. Mater. 2003;317:32-45.

21. Zinkle S.J., Maziasz P.J., Stoller R.E., J. Nuc. Mater. 1993;206:266-286.

22. Bruemmer S.M., Simonen E.P., Scott P.M., Andersen P.L., Was G.S., Nelson J.L., J. Nuc. Mater. 1999;274:299-314.

23. Schibli R., Schäublin R., J. Nuc. Mater. 2013;442:S761-S767.

24. Dai Y., Jia X., Chen J.C., Sommer W.F., Victoria M., Bauer G.S., J. Nuc. Mater. 2001;296:174-182.

25. Heald P.T., Philos. Mag. 1975;31:551.

26. Garner F.A., Toloczko M.B., Sencer B.H., J. Nuc. Mater. 2000;276:123-142.

27. Sencer B.H, Garner F.A. J. Nuc. Mater. 2000;283-287:164-168.

28. Little E.A. and Stow D.A., J. Nuc. Mater. 1979;87: 25-39.

29. Surh M.P., Sturgeon J.B., Wolfer W.G., "The Incubation Period for Void Swelling and its Dependence on Temperature, Dose Rate, and Dislocation Structure Evolution”, Effects of Radiation on Materials, ASTM STP 1447, Grossbeck ML, Ed., ASTM International, West Conshohocken, PA, 2003.

30. Toloczko M.B., Garner F.A., Voyevodin V.N., Bryk V.V., Borodin O.V., Mel'nychenko V.V., Kalchenko A.S., J. Nuc. Mater. 2014;453:323-333.

31. Sun C., Zheng S., Wei C.C., Wu Y., Shao L., Yang Y., Hartwig K.T., Maloy S.A., Zinke S.J., Allen T.R., Wang H., Zhang X., Sci. Rep. 2015;5:7801. 
32. Allen TR, Busby JT. Jom 2009;61:29.

33. Was GS, Wharry JP, Frisbie B, Wirth BD, Morgan D, Tucker JD, Allen TR. Journal of Nuclear Materials 2011;411:41.

34. Was G.S., Busby J., Andresen P.L., ASM Handbook 2006;13:386.

35. Busby J.T., Was G.S., Kenik E.A., J. Nuc. Mater. 2002;302:20.

36. Lu Z., Faulkner R.G., Sakaguchi N., Kinoshita H., Takahashi H., Flewitt P.E.J., J. Nuc. Mater. 2004;329:1017.

37. Lu Z., Faulkner R.G., Flewitt P.E.J., J. Nuc. Mater. 2007;367:621.

38. Lu Z., Faulkner R.G., Flewitt P.E.J., Mater. Sci. Eng. A 2006;437:306.

39. Was G.S., Busby J.T., Allen T., Kenik E.A., Jensson A., Bruemmer S.M., Gan J., Edwards A.D., Scott P.M., Andreson P.L., J. Nuc. Mater. 2002;300:198.

40. Wharry J.P., Jiao Z., Was G.S., J. Nuc. Mater. 2012;425:117.

41. Ardell A.J., "Radiation-induced solute segregation in alloys. Materials Issues for Generation IV Systems", Springer, 2008. p.285.

42. Allen T.R., Was G.S., "Radiation-enhanced diffusion and radiation-induced segregation. Radiation Effects in Solids", Springer, 2007. p.123.

43. Allen T.R., Busby J.T., Was G.S., Kenik E.A., J. Nuc. Mater 1998;255:44.

44. Allen T.R., Was G.S., Acta Mater. 1998;46:3679.

45. Watanabe S., Sakaguchi N., Kurome K., Nakamura M., Takahashi H., J. Nuc. Mater. 1997;240:251.

46. Stepanov I.A., Pechenkin V.A., Konobeev Y.V., J. Nuc. Mater. 2004;329:1214.

47. Tucker J.D., Najafabadi R., Allen T.R., Morgan D., J. Nuc. Mater. 2010;405:216.

48. Lu Z., Faulkner R.G., Was G., Wirth B.D., Scr. Mater. 2008;58:878. 
49. Wharry J.P., Jiao Z., Shankar V., Busby J.T., Was G.S., J. Nuc. Mater. 2011;417:140.

50. Bachhav M., Odette G.R., Marquis E.A., Scr. Mater. 2014;74:48.

51. Bonny G., Terentyev D., Malerba L., Scr. Mater. 2008;59:1193.

52. Kuksenko V., Pareige C., Pareige P., J. Nuc. Mater. 2013;432:160.

53. Gelles D.S., Schäublin R.E., Mater. Sci. Eng. A 2001;309-310:82.

54. Bergner F., Pareige C., Hernández-Mayoral M., Malerba L., Heintze C., J. Nuc. Mater 2014;448:96.

55. Bachhav M., Odette G.R., Marquis E.A., J. Nuc. Mater. 2014;454:381.

56. Snead L.L., Hay J.C., J. Nuc. Mater. 1999;273:213.

57. Inui H., Mow H., Fujita H., Acta Metall. 1989;37:1337.

58. Weber W.J., Yu N., Wang L.M., Hess N.J., J. Nuc. Mater. 1997;244:258.

59. Zinkle S.J., Snead L.L., Nucl. Instrum. Methods Phys. Res. Sect. B 1996;116:92.

60. Jin E, Niu L-S. Physica B: Condensed Matter 2011;406:601.

61. Weber W.J., Wang L.M., Yu N., Hess N.J., Mater. Sci. Eng. A 1998;253:62.

62. Bolse W., Nucl. Instrum. Methods Phys. Res. Sect. B 1999;148:83.

63. Debelle A., Boulle A., Chartier A., Gao F., Weber W.J., Phys. Rev. B 2014;90:174112.

64. Devanathan R., Weber W.J., Gao F., J.Appl. Phys. 2001;90:2303.

65. Malerba L., Perlado J.M., Phys. Rev. B 2002;65:045202.

66. Rong Z., Gao F., Weber W.J., Hobler G., J. Appl. Phys. 2007;102:103508.

67. Lin Y.-R., Ho C.-Y., Chuang, W.-T., Ku C.-S., Kai, J.-J., J. Nucl. Mater. 2014;455:292296.

68. Certain A., Kuchibhatla S., Shutthanandan V., Hoelzer D. T., Allen T. R., J. Nucl. Mater. 2013;343:311-321. 
69. Meslin E., Lambrecht M., Hernandez-Mayoral M., Bergner F., Malerba L., Pareige P., Radiguet B., Barbu A., Gomez-Briceno D., Ulbricht A., Almazouzi A., J. Nucl. Mater. 2010;406:73-83.

70. Becquart C. S., Wirth B. D., "Kinetic Monte Carlo Simulations of Irradiation Effects, in Comprehensive Nuclear Materials”, edited by R. J. M. Konings (Elsevier, Oxford, 2012).

71. Wirth B. D., Odette G. R., Marian J., Ventelon L., Young-Vandersall J. A., Zepeda-Ruiz L. A., J. Nuc. Mater. 2004;329-333 (Part A):103-111.

72. Stan M., Mater. Today 2009:12:20-28.

73. Stoller R. E., Golubov S. I., Domain C., Becquart C. S., J. Nuc. Mater. 2008;382:77-90.

74. Golubov S. I., Barashev A. V., Stoller R. E., "Radiation Damage Theory, in Comprehensive Nuclear Materials”, edited by R. J. M. Konings (Elsevier, Oxford, 2012).

75. Vincent E., Becquart C. S., Pareige C., Pareige P., Domain C., J. Nuc. Mater. 2008;373:387-401.

76. Jourdan T., Soisson F., Clouet E., Barbu A., Acta Mater. 2010;58:3400-3405.

77. Hu S., Henager Jr. C. H., J. Nuc. Mater. 2009;394:155-159.

78. Ghoniem N. M., "Dislocation Dynamics, in Comprehensive Nuclear Materials", edited by R. J. M. Konings (Elsevier, Oxford, 2012).

79. Orowan E., "Symposium on Internal Stresses in Metals and Alloys" (Institute of Metals, 1948).

80. Hardouin Duparc A., Moingeon C., Smetniansky-de-Grande N., Barbu A., J. Nuc. Mater. 2002;302:143-155.

81. Kohnert A. A., Wirth B. D., J. Appl. Phys. 2015;117:154305.

82. Xu D., Wirth B. D., Li M., Kirk M. A., Acta Mater. 2012;60:4286-4302. 
83. Topbasi C., Motta A. T., Kirk M. A., J. Nuc. Mater. 2015;425:48-53.

84. Kaoumi D., Adamson J., Kirk M., J. Nuc. Mater. 2014;445:12-19.

85. Wirth B. D., Hu X., Kohnert A., Xu D., J. Mater. Res. 2015;30:1440-1455.

86. Martínez E., Senninger O., Fu C.-C., Soisson F., Phys. Rev. B 2012;86:224109.

87. Bonny G., Terentyev D., Malerba L., J. Nucl. Mater. 2009;385:278-283.

88. Chen L.-Q., Annu. Rev. Mater. Res. 2002;32:113-140.

89. Bellon P., "Phase Field Methods, in Comprehensive Nuclear Materials", edited by R. J. M. Konings (Elsevier, Oxford, 2012).

90. Cahn J. W., Hilliard J. E., J. Chem. Phys. 1958;28:258-267.

91. Allen S. M., Cahn J. W., Acta Metall. 1979;27:1085-1095.

92. Tonks M. R., Gaston D., Millett P. C., Andrs D., Talbot P., Comput. Mater. Sci. 2012;51:20-29.

93. Gaston D., Newman C., Hansen G., Lebrun-Grandié D., Nucl. Eng. Des. 2009;239:17681778.

94. Tonks M. R., Millett P. C., Nerikar P., Du S., Andersson D., Stanek C. R., Gaston D., Andrs D., Williamson R., J. Nucl. Mater. 2013;440:193-200.

95. Chakraborty, P., Zhang, Y., Tonks, M. R., Comput. Mater. Sci. 2016;113:38-52.

96. Bai, X.-M., Tonks, M. R., Zhang, Y., Hales, J., J. Nucl. Mater. 2016;470:208-215.

97. Ghoniem N. M., Walgraef D., Zinkle S. J., J. of Comput.-Aided Mater. Des. 2001;8:1-38.

98. Redner. S., “A Guide to First-Passage Processes”, Cambridge University Press, Cambridge, England, 2001.

99. Woo C. H., Frank W., J. Nucl. Mater. 1985;137:7-21. 
100. Badillo A., Bellon P., Averback R. S., Modell. Simul. Mater. Sci. Eng. 2015;23:035008.

101. Ardell A. J., "Radiation-Induced Solute Segregation in Alloys, in Materials Issues for Generation IV Systems", edited by V. Ghetta et al. (Springer Netherlands, 2008).

102. Was G. S., Wharry J. P., Frisbie B., Wirth B. D., Morgan D., Tucker J. D., Allen T. R., J. Nucl. Mater. 2011;411:41-50.

103. Wharry J. P., Was G. S., Acta Mater. 2014;65:42-55. 